\title{
Creep Deformation and Dynamic Grain Growth in an Interstitial-Free Steel
}

\begin{abstract}
RYANN E. RUPP, PHILIP J. NOELL, and ERIC M. TALEFF
Dynamic grain growth is demonstrated to be much faster than static grain growth in a body-centered-cubic, interstitial-free steel sheet material at $850^{\circ} \mathrm{C}$. Dynamic grain growth occurs during concurrent plastic deformation at elevated temperature, whereas static grain growth occurs during static annealing. Grain growth during steady-state plastic flow in tension at $850{ }^{\circ} \mathrm{C}$ to a true strain of 0.2 at a true-strain rate of $10^{-4} \mathrm{~s}^{-1}$ doubled grain size, while static annealing for the same time produced no increase in grain size. This is described as dynamic normal grain growth (DNGG) because no abnormally large grains were observed. The recrystallized microstructure of the steel demonstrated a log-normal distribution of grain sizes. DNGG produced bimodal grain size distributions that deviate from the theoretical expectation of a simple shift to larger sizes during normal growth. The bimodal distributions contained a remnant of small grains that were not consumed during grain growth. DNGG produced a crystallographic texture that is unique from both the recrystallized material and that produced by lattice rotation alone. DNGG strengthened the $\{111\}\langle 110\rangle$ and $\{111\}\langle 112\rangle$ components of the strong $\gamma$-fiber component in the original recrystallization texture. Lattice rotation from tensile deformation, by contrast, strengthened the $\alpha$-fiber components that intersect the original $\gamma$-fiber.
\end{abstract}

https://doi.org/10.1007/s11661-020-06014-6

(C) The Minerals, Metals \& Materials Society and ASM International 2020

\section{INTRODUCTION}

INTERSTITIAL-FREE (IF) steels, also known as ultra-low-carbon and extra-low-carbon steels, are used in industry because of their high ductilities and formabilities. ${ }^{[1]}$ Formability, especially deep drawability of sheet, can be improved through microstructure control. Small alloying additions of $\mathrm{Ti}$ and/or $\mathrm{Nb}$ are used to control grain size. ${ }^{[1]}$ Crystallographic texture is controlled through rolling and annealing schedules. A high Lankford coefficient, $r$, is often used as an indication of deep drawability. ${ }^{[2]}$ A strong $\gamma$-fiber texture, wherein the $\langle 111\rangle$ is perpendicular to the sheet normal, increases $r$ and improves deep drawability. ${ }^{[3,4]}$ This desirable strong $\gamma$-fiber texture is developed during recrystallization following heavy cold rolling reductions of steel sheet. ${ }^{[3]}$ Ukena reported that the average Lankford coefficient, $\bar{r}$ value, was increased beyond that produced by static annealing at $800^{\circ} \mathrm{C}$ alone when a tensile stress of $20 \mathrm{MPa}$ was applied to a cold-rolled, low-carbon (0.02 wt pct)

RYANN E. RUPP is with the Idaho National Laboratory, $1955 \mathrm{~N}$. Fremont Ave., Idaho Falls, ID 83415. PHILIP J. NOELL is with the Sandia National Laboratories, P.O. Box 5800, Albuquerque, NM 87185-0889. ERIC M. TALEFF is with The University of Texas at Austin, Department of Mechanical Engineering, 204 East Dean, Keeton St., Stop C2200, Austin, TX 78712. Contact e-mail: taleff@utexas.edu

Manuscript submitted May 7, 2020.

Article published online October 1, 2020
Al-killed steel sheet. ${ }^{[5,6]}$ The increase in $\bar{r}$ from annealing under a tensile stress resulted from an increase in the intensity of the $\{111\}\langle 110\rangle$ texture component, part of the $\gamma$-fiber. The cause of this unusual texture change during annealing under tensile stress could not be precisely established. The same value of $\bar{r} \approx 1.9$ was produced by annealing times up to $10 \mathrm{~s}$ for specimens with and without an applied tensile stress. Because this time is probably sufficient for recrystallization, recrystallization behaviors are unlikely to be the cause of the observed texture difference. The $\bar{r}$ value increased beyond 1.9 with additional annealing time, and the increase in specimens under tensile stress was more rapid than in unstressed specimens. For $300 \mathrm{~s}$ annealing at $800^{\circ} \mathrm{C}$, an unstressed specimen achieved $\bar{r}=2.02$ while a stressed specimen achieved $\bar{r}=2.16$. This result points toward two potential causes of the observed texture change: 1 . crystal rotation from slip deformation and 2. an increased rate of grain growth during plastic deformation, i.e., dynamic grain growth. The present investigation was undertaken to identify the mechanism that produces this crystallographic texture change. An IF steel with a small Ti addition to provide grain size control was chosen for study.

Grain growth is important to this study and is among the several phenomena fundamentally important to the processing of metals and alloys. The grain structures and crystallographic textures developed during grain growth can strongly influence the mechanical and 
physical properties of a material. Grain growth in a fully recrystallized material, which is the only case considered here, can be categorized as either normal or abnormal..$^{7,8]}$ Normal grain growth is characterized by a uniform increase in grain size with time. An initial grain size distribution, for which the log-normal type of distribution is typical, will ideally shift to larger grain sizes while retaining its general shape during normal grain growth. ${ }^{[8]}$ Abnormal grain growth, also known as secondary recrystallization, is characterized by a small number of grains that grow by rapidly consuming their smaller neighboring grains. ${ }^{[7,8]}$ This produces a bimodal distribution of grain sizes from an initially unimodal distribution. ${ }^{[8]}$ Grain growth can be further categorized by whether it occurs during static annealing or during plastic deformation, a dynamic condition, at elevated temperature. These considerations produce four categories of grain growth: 1. static normal grain growth (SNGG), 2. static abnormal grain growth (SAGG), 3 . dynamic normal grain growth (DNGG), and 4. dynamic abnormal grain growth (DAGG). Most studies of grain growth in the literature focus on cases of static growth, as these are much easier to assess experimentally than are the dynamic cases. However, the literature does contain information from a number of studies concerned with dynamic normal grain growth ${ }^{[9-15]}$ and dynamic abnormal grain growth. ${ }^{\text {16-22] }}$ This study investigates the nature of grain growth in an IF steel for both static and dynamic conditions.

The quantitative description of crystallographic texture is a rather complex process, and the literature is replete with methods for the visual representation of texture. ${ }^{[23,24]}$ All texture information in the present investigation was derived from microtexture data acquired using the electron backscatter diffraction (EBSD) technique in a scanning electron microscope (SEM). ${ }^{[25]}$ The microtexture data of this study are presented as inverse-pole-figure (IPF) maps. ${ }^{[25]}$ Accumulated microtexture data were used to calculate orientation distribution functions (ODFs) to represent macrotexture, and these are presented as inverse pole figures and as Euler maps. ${ }^{[23,24]}$ Among the several possible notations, the Bunge notation for Euler space is used throughout this study. ${ }^{[23,24]}$ Visual representations of data in Euler space are limited here to the $\varphi_{2}=45^{\circ}$ slices shown in Figure 1, which are considered the most instructive for this study. The region of Euler space required to be represented depends on both crystal symmetry and specimen symmetry. Because the tensile coupons used in this study were excised at three different angles relative to the IF steel sheet rolling direction, as shown in Figure 2, specimen symmetry varied with tensile specimen orientation. For the $\theta=0$ and $90^{\circ}$ specimen orientations, bilateral specimen symmetry is preserved, and the representation of $\varphi_{1}$ values requires only a range of $0 \leq \varphi_{1}<45^{\circ}$. The $\theta=45^{\circ}$ specimen orientation breaks that symmetry and requires presentation over the range $0 \leq \varphi_{1}<180^{\circ}$. These cases are shown in Figure 1. Euler maps require definition of a reference orientation, which is typically affixed to the rolling direction (RD), long-transverse direction (LTD), and short-transverse direction (STD) for a rolled sheet material, i.e., the sheet frame. A different reference orientation is used in this study. Throughout this study, the reference orientation is fixed to the tensile specimen frame by the tensile direction (TD) and tensile long-transverse direction (TLTD). The tensile specimen frame only coincides with the sheet frame for the $\theta=0^{\circ}$ specimen orientation; see Figure 2. This definition was chosen because it is most convenient for evaluating the texture changes produced by tensile deformation. The $\gamma$-fiber texture component is clearly demonstrated in the $\varphi_{2}=45 \mathrm{deg}$ Euler maps of Figure 1, which is one reason that the $\varphi_{2}=45 \mathrm{deg}$ slice from Euler space is so instructive. Also shown in the $\varphi_{2}=45 \mathrm{deg}$ slice is the $\alpha$-fiber texture component, for which $\langle 110\rangle$ is parallel to the TD, and to the RD for the $\theta=0 \mathrm{deg}$ specimen orientation only. The intersections of the $\alpha$-fiber with the $\gamma$-fiber are important to understanding the results of this study, and these points of intersection are labeled in Figure 1. Figures 1 and 2 are intended to be used as references for understanding the experimental data and analyses presented herein.

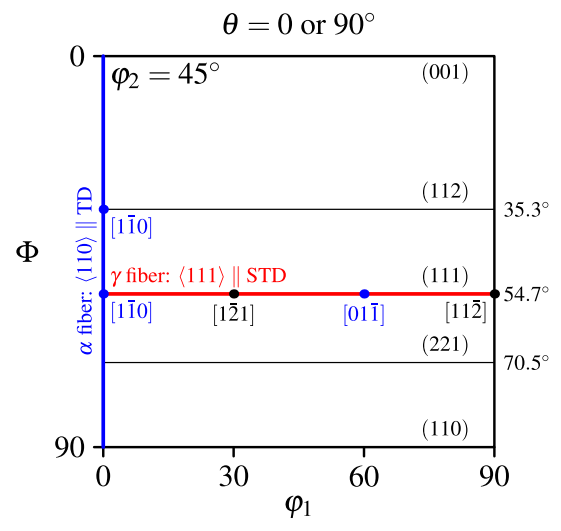

(a)

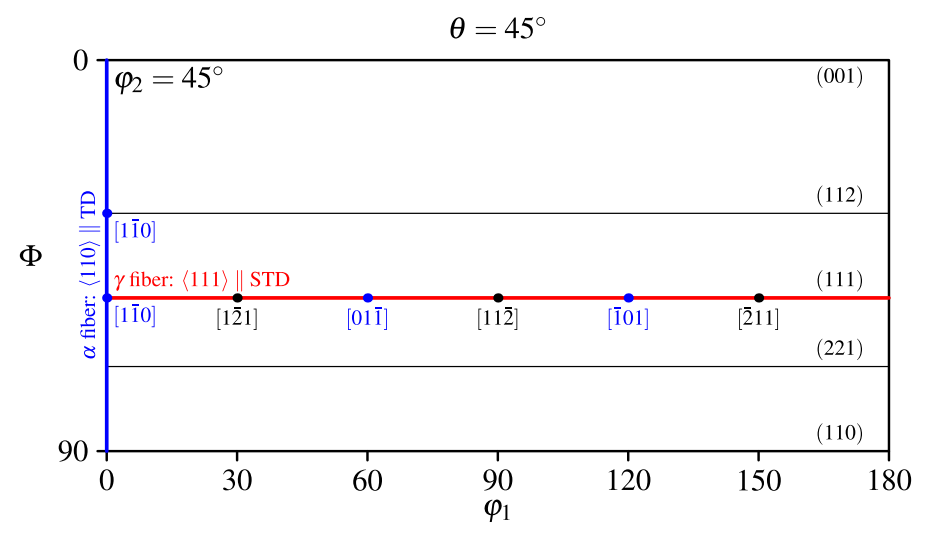

(b)

Fig. $1-\mathrm{A} \varphi_{2}=45 \mathrm{deg}$ slice from Euler space (Bunge notation) is shown for specimens with the TD oriented at $(a) \theta=0$ and 90 deg from the $\mathrm{RD}$ and $(b) \theta=45 \mathrm{deg}$ to the RD. The $\alpha$ - and $\gamma$-fiber texture components are indicated, as well as intersections of the $\alpha$-fiber with the $\gamma$-fiber. The tensile specimen reference frame defines the reference orientations for these diagrams. 


\section{EXPERIMENTAL PROCEDURES}

The material investigated is a titanium-added, interstitial-free (IF) steel sheet provided by I/N Tek (New Carlisle, IN), a joint venture of ArcelorMittal and Nippon Steel \& Sumitomo Metal Corporation. The composition of the IF steel, as provided by the supplier, is presented in Table I. The sheet was received in the cold-rolled state with a thickness of $0.69 \mathrm{~mm}$. The RD, LTD, and STD were recorded for the as-received material and documented throughout testing. Based on the measured carbon content, this IF steel is predicted to remain ferrite, the body-centered-cubic (BCC) crystal structure of the $\alpha$ phase, to a minimum of $890^{\circ} \mathrm{C}^{[1]}$ Because the titanium addition combines with much of the available carbon and nitrogen, this prediction is a lower bound on the temperature at which the first austenite, the face-centered-cubic (FCC) crystal structure of the $\gamma$ phase, is likely to form. Temperature was monitored during all elevated-temperature experiments to ensure that the material remained within the ferrite phase field throughout testing. No indications of transformation to austenite were observed.

Because the IF steel was received in the cold-worked state and was to be tested after recrystallization, its recrystallization behavior was investigated. Annealing experiments were conducted at $850^{\circ} \mathrm{C}$ in a salt pot for times up to $1802 \mathrm{~s}$. Rockwell B hardness (HRB) was

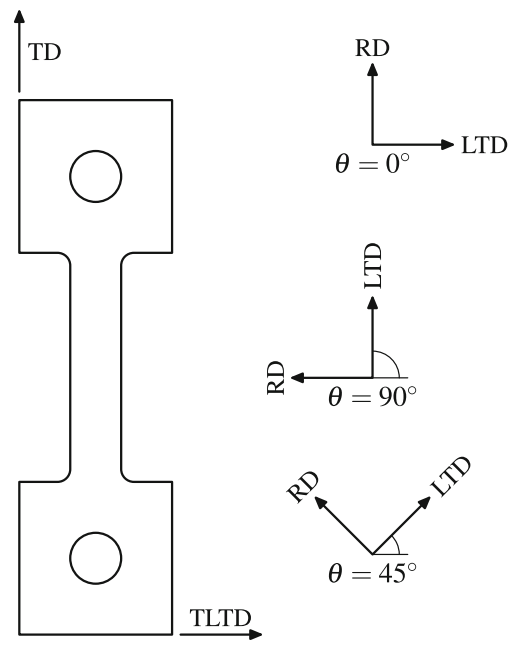

Fig. 2-The tensile coupon geometry is shown with the three specimen orientations relative, by rotation angle $\theta$, to the original sheet material reference frame. Reference directions are the tensile direction (TD), tensile long-transverse direction (TLTD), sheet rolling direction (RD), and sheet long-transverse direction (LTD). The short-transverse direction (STD), identical to the sheet thickness direction, is the same for all cases. measured before and after annealing to determine the minimum time required for recrystallization. A minimum of five (5) hardness measurements were performed for each annealed condition, following the guidelines in ASTM E18-17 $7^{\epsilon 1} \cdot{ }^{[26]}$ All specimens subjected to tension tests were fully recrystallized either through a separate annealing treatment prior to testing or, for elevated-temperature tension tests, by holding the specimen at the test temperature sufficiently long to ensure recrystallization prior to tensile straining.

Coupons for tensile testing were machined from the as-received material in the geometry demonstrated by Figure 2, with a gauge length of $25.4 \mathrm{~mm}$, gauge width of $6.44 \mathrm{~mm}$, and a shoulder radius of $1.6 \mathrm{~mm}$ between the gauge and grip regions. The as-received thickness of the sheet, $0.69 \mathrm{~mm}$, was retained. Tensile coupons were produced with the TD in one of three different orientations: (1) TD along the RD $(\theta=0 \mathrm{deg})$, (2) TD along the LTD and perpendicular to the RD $(\theta=90 \mathrm{deg})$, and (3) TD at $45 \mathrm{deg}$ to the RD and LTD $(\theta=45 \mathrm{deg})$. The TLTD and TD are defined in reference to the machined tensile coupon. The relationships between these specimen directions and the original sheet directions are shown Figure 2. Note that the STD is identical between the tensile specimen and original sheet reference frames.

Tensile specimens were tested at room temperature in each of the three specimen orientations $(\theta=0,90$, and $45 \mathrm{deg}$ ) using an extensometer. Tensile specimens were recrystallized prior to testing by annealing in a sealed stainless-steel bag containing titanium chips, to scavenge oxygen and nitrogen, at $850^{\circ} \mathrm{C}$ for 30 minutes. Room-temperature tensile tests were conducted at a constant cross-head speed that provided an engineering-strain rate of $8.3 \times 10^{-4} \mathrm{~s}^{-1}$. Tensile specimens were also tested at elevated temperatures. Flow stress data were acquired at temperatures of 840 to $890^{\circ} \mathrm{C}$ by testing in a vacuum furnace with pin-loading grips. The vacuum furnace controlled specimen temperature to approximately $\pm 10{ }^{\circ} \mathrm{C}$, based upon calibration experiments conducted without a specimen. A universal testing machine with a cross-head driven by ball screws was used with computer control to apply a constant true-strain rate in the range of $10^{-5}$ to $10^{-3} \mathrm{~s}^{-1}$ during testing, calculated assuming uniform specimen deformation and no necking. A vacuum in the range of $10^{-5}$ to $10^{-6}$ Torr was maintained during testing, which prevented specimen oxidation. Specimens were held at temperature for approximately $1 \mathrm{hr}$. prior to tensile straining to ensure complete recrystallization and temperature uniformity. Because specimens required more than 10 minutes to cool after tensile testing in the vacuum furnace, the cooling rate was inadequate to

Table I. Composition of the Steel in Weight Percent, as Provided by the Manufacturer

\begin{tabular}{lllllllllll}
\hline $\mathrm{Mn}$ & $\mathrm{Al}$ & $\mathrm{Ti}$ & $\mathrm{Cr}$ & $\mathrm{Cu}$ & $\mathrm{Ni}$ & $\mathrm{S}$ & $\mathrm{P}$ & $\mathrm{Nb}$ & $\mathrm{Si}$ & $\mathrm{Mo}$ \\
0.1319 & 0.065 & 0.0428 & 0.0294 & 0.0188 & 0.0185 & 0.0118 & 0.0112 & 0.0097 & 0.0049 & 0.004 \\
& & & & & & & & & & $\mathrm{Ca}$ \\
$\mathrm{As}$ & $\mathrm{N}$ & $\mathrm{C}$ & $\mathrm{Pb}$ & $\mathrm{Sn}$ & $\mathrm{V}$ & $\mathrm{Sb}$ & $\mathrm{B}$ & $\mathrm{Fe}$ & $\mathrm{Ca}$ \\
0.0034 & 0.00248 & 0.0024 & 0.001 & 0.001 & 0.001 & 0.0007 & 0.0001 & 0.0001 & bal. \\
\hline
\end{tabular}


preserve dislocation substructure for subsequent observation. Specimens from these tests in vacuum were used to measure flow stress as a function of temperature and strain rate as well as grain sizes and crystallographic textures. Elevated-temperature tensile tests to preserve dislocation substructure were conducted by testing in air and then quenching the specimen with a water spray while it was held under a constant load. Both the rapid quenching and the constant load on the specimen are important to preserve dislocation substructure produced during tensile straining at temperature. A servo-hydraulic test frame with computer control was used to provide a constant true-strain rate during straining and to hold load constant during subsequent quenching. Specimens of all three orientations $(\theta=0,90$, and $45 \mathrm{deg}$ ) were tested at $850^{\circ} \mathrm{C}$, using a three-zone resistance furnace to control temperature to within \pm 3 ${ }^{\circ} \mathrm{C}$, as measured by a type $\mathrm{K}$ thermocouple adjacent to the specimen. The specimen was held under a small load of less than $10 \mathrm{~N}$ while heating to and stabilizing at $850{ }^{\circ} \mathrm{C}$, during which recrystallization occurred. Tensile straining was then applied at a constant true-strain rate of $10^{-4} \mathrm{~s}^{-1}$, calculated assuming uniform specimen deformation and no necking, to true strains of either 0.1 or 0.2 . Control was then switched to apply a constant load equal to that at the end of the tension test. The furnace was then immediately opened, and the specimen was quenched by a water spray until it reached a temperature low enough for handling. Because oxidation during testing reduced the specimen cross section, flow stress data were not acquired from these tests. Further details on the implementation of mechanical testing procedures are available in Reference 27 . The conditions of tensile testing are summarized in Table II.

The microstructures of statically recrystallized specimens, specimens' tensile tested at room temperature, and specimens tested at $850^{\circ} \mathrm{C}$ and $10^{-4} \mathrm{~s}^{-1}$ in both air and vacuum were characterized using a scanning

Table II. Experimental Conditions for Tension Tests by Temperature $(T)$, Strain Rate ( $\dot{e}$ for Engineering-Strain Rate and $\dot{\epsilon}$ for True-Strain Rate), Specimen Orientation $(\theta)$, and Total True Strain Accumulated $(\epsilon)$

\begin{tabular}{llcc}
\hline$T(\operatorname{degC})$ & Strain Rate $\left(\mathrm{s}^{-1}\right)$ & $\theta(\mathrm{deg})$ & $\epsilon$ \\
\hline 25 & $\dot{e}=3.3 \times 10^{-5}$ & 0 & 0.13 \\
25 & $\dot{e}=3.3 \times 10^{-5}$ & 0 & 0.22 \\
25 & $\dot{e}=3.3 \times 10^{-5}$ & 90 & 0.12 \\
25 & $\dot{e}=3.3 \times 10^{-5}$ & 90 & 0.22 \\
25 & $\dot{e}=3.3 \times 10^{-5}$ & 45 & 0.12 \\
25 & $\dot{e}=3.3 \times 10^{-5}$ & 45 & 0.22 \\
840 & $\dot{\epsilon}=10^{-3}$ & 0 & 0.49 \\
850 & $\dot{\epsilon}=10^{-5}$ & 0 & 0.20 \\
850 & $\dot{\epsilon}=10^{-4}$ & 0 & 0.10 \\
850 & $\dot{\epsilon}=10^{-4}$ & 0 & 0.20 \\
850 & $\dot{\epsilon}=10^{-4}$ & 90 & 0.10 \\
850 & $\dot{\epsilon}=10^{-4}$ & 90 & 0.20 \\
850 & $\dot{\epsilon}=10^{-4}$ & 45 & 0.10 \\
850 & $\dot{\epsilon}=10^{-4}$ & 45 & 0.20 \\
890 & $\dot{\epsilon}=10^{-4}$ & 0 & 0.53 \\
890 & $\dot{\epsilon}=10^{-3}$ & 0 & 0.54 \\
\hline
\end{tabular}

electron microscope (SEM). Specimens tested at elevated temperature in air were pickled in a solution of 6 to 12 pct sulfuric acid in water, by volume, at temperatures from $77{ }^{\circ} \mathrm{C}$ to $88{ }^{\circ} \mathrm{C}$ to remove oxide scale prior to metallographic preparation. Specimens were ground and polished to a final polish with colloidal silica in distilled water. No etching was applied to the metallographic specimens. Microstructures were observed in an SEM using backscattered electron (BSE) channeling contrast to reveal grains. SEM-BSE images were used to measure grain sizes by the lineal-intercept technique described in ASTM E112-13. ${ }^{[28]}$ Electron backscatter diffraction (EBSD) was conducted using a Philips/FEI CL30 environmental SEM instrument equipped with an Oxford HKL Nordlys ${ }^{\text {TM }}$ detector and AZtecHKL ${ }^{\text {TM }}$ software. The camera resolution used was $1344 \times 1023$ pixles. A step size of $2 \mu \mathrm{m}$ was used for acquisitions at an accelerating voltage of $20 \mathrm{kV}$ and a spot size of 5 . The working distance was typically $15 \pm 3 \mathrm{~mm}$, and a standard specimen tilt of $70 \mathrm{deg}$ was applied. Acquisition binning was set to $4 \times 4$ using both the automatic and static background corrections. A set of ten (10) frames was collected for static background correction.

EBSD data were processed using custom Mathematica $^{\text {TM[29] }}$ scripts $^{[17,18,30]}$ and the MTEX open-source toolbox $^{[31]}$ (version 4.0.23) for Matlab ${ }^{\text {TM }}{ }^{32]}$ Orientation distribution functions (ODFs) were calculated from EBSD data using the MTEX software. EBSD data were analyzed by first correcting for specimen misalignment by enforcing specimen symmetry on a $\{200\}$ pole figure from the data, calculated using custom software scripts, and then applying a correction rotation to the data. The mean standard alignment error was $\pm 1.73 \mathrm{deg}$, and the corrected alignment error was $\pm 0.20 \mathrm{deg}$. Details on this correction process are provided in Reference 27. For analysis, data were represented as inverse pole figures (IPFs) and IPF maps. ODFs calculated from EBSD datasets were represented in Euler space referenced to the tensile specimen frame, with plots of the $\varphi_{2}=45$ deg slice being particularly instructive. All intensities were calculated as multiples of random. EBSD data were segmented into grains using custom software scripts applying a $5 \mathrm{deg}$ minimum disorientation to define a high-angle grain boundary and requiring a minimum grain size of five (5) pixels. The sizes of individual grains within the EBSD datasets $^{[33]}$ were measured from individual segmented grain area $A_{i}$, excluding grains intersecting image boundaries, and converted to lineal-intercept grain diameters as $\ell_{i}=\sqrt{\pi A_{i} / 4}$, per the method presented in ASTM E112-13. ${ }^{[28]}$ The grain aspect ratio of each grain not intersecting the image boundary was calculated using the corresponding function in the MTEX package, and these values were averaged for each material condition.

To confirm the effects caused by lattice rotation during tensile deformation, simulations were conducted using the viscoplastic self-consistent (VPSC) model and VPSC software version 7c. ${ }^{[34]}$ EBSD data including over 500 grains, their crystallographic orientations, and sizes were acquired from the recrystallized IF steel and used as inputs to the VPSC simulations. Simulations were conducted to true strains of 0.1 and 0.2 in 20 steps for 
each case. All three families of slip for BCC iron were allowed, i.e., slip along the $\langle 111\rangle$ directions in the $\{110\}$, $\{112\}$, and $\{123\}$ planes. Test simulations allowing slip on only the $\{110\}$ and $\{112\}$ planes produced very similar results. Simulations were conducted for each of the three tensile specimen orientations $(\theta=0,90$, and $45 \mathrm{deg})$. Details of the simulations and the input files used are available in Reference 27.

\section{RESULTS}

\section{A. The Recrystallized Condition}

Data from recrystallization experiments are presented in Figure 3. A typical recrystallized microstructure produced by annealing the as-received IF steel sheet material at $850^{\circ} \mathrm{C}$ for $30 \mathrm{~min}$. is shown in Figure 3(a) as a BSE image. The IF steel recrystallized to a uniformly equiaxed microstructure. The lineal-intercept grain size of this recrystallized material was measured as $\bar{d}_{\mathrm{RX}}=13 \pm 1 \mu \mathrm{m}$ using multiple BSE images. Rockwell $\mathrm{B}$ hardness (HRB) measured after annealing in a salt pot at $850{ }^{\circ} \mathrm{C}$ is plotted as a function of the logarithm of annealing time in Figure 3(b). The drop in hardness at approximately $10 \mathrm{~s}$ indicates recrystallization. Full recrystallization occurred within $30^{\circ} \mathrm{C}$ at $850{ }^{\circ} \mathrm{C}$

EBSD data were acquired from IF steel recrystallized by annealing at $850{ }^{\circ} \mathrm{C}$ for $30 \mathrm{~min}$. to evaluate crystallographic texture. These EBSD data are presented in Figure 4(a) as inverse pole figures (IPFs) presented relative to the specimen TD, TLTD, and STD for each of the three tensile specimen orientations $(\theta=0,90$, and $45 \mathrm{deg})$. These IPFs demonstrate a strong $\gamma$-fiber texture component in the recrystallized material. A secondary $\alpha$-fiber component is also evident and is most readily observed in the TD IPF of the $\theta=0 \mathrm{deg}$ specimen orientation, for which the TD is parallel to the sheet RD. The $\alpha$-fiber component is also evident in the TLTD IPF of the $\theta=90 \mathrm{deg}$ specimen orientation, for which the TLTD is parallel to the sheet RD; the $\alpha$-fiber component is split between the TD and TLTD IPFs for the $\theta=45 \mathrm{deg}$ specimen orientation. An orientation distribution function (ODF) was constructed using the EBSD data from the recrystallized IF steel. This ODF is presented in $\varphi_{2}=45 \mathrm{deg}$ slices from Euler space in Figure 4(b) for the three different tensile specimen orientations. These Euler maps are presented in reference to the tensile specimen frame, not the original sheet reference frame. The specimen reference frame is used in all the Euler maps presented herein. The ideal $\gamma$-fiber texture component is shown as a line in Figure 4(b) to emphasize the strong $\gamma$-fiber component in the recrystallized IF steel texture, regardless of specimen orientation. Note that the Euler map for the $\theta=45 \mathrm{deg}$ specimen orientation requires plotting $0 \leq \varphi_{1}<180 \mathrm{deg}$ because of reduced specimen symmetry relative to the $\theta=0$ and $90 \mathrm{deg}$ cases. Note that the $\alpha$-fiber component is evident where it intersects the dominant $\gamma$ fiber; see Figure 1 for these points of intersection. Note also that the crystallographic texture relative to the tensile specimen frame is slightly different for each tensile specimen orientation, a result of the different tensile specimen reference frames only.

\section{B. Room-Temperature Tensile Data and VPSC Simulations}

Tensile data from room-temperature experiments of the recrystallized IF steel are presented as true stress vs true strain in Figure 5 for the three different specimen orientations. These tests were conducted to a tensile true strain of approximately 0.2 , which is well short of the strains necessary for flow localization or rupture. The yield-point phenomenon is evident, which indicates some interstitial content not scavenged by the $\mathrm{Ti}$ addition. A slight strength difference is evident between the three specimen orientations. Following the Lüders region, the $\theta=45 \mathrm{deg}$ orientation demonstrates the highest strength, followed by the $90 \mathrm{deg}$ and then $0 \mathrm{deg}$ specimen orientations.

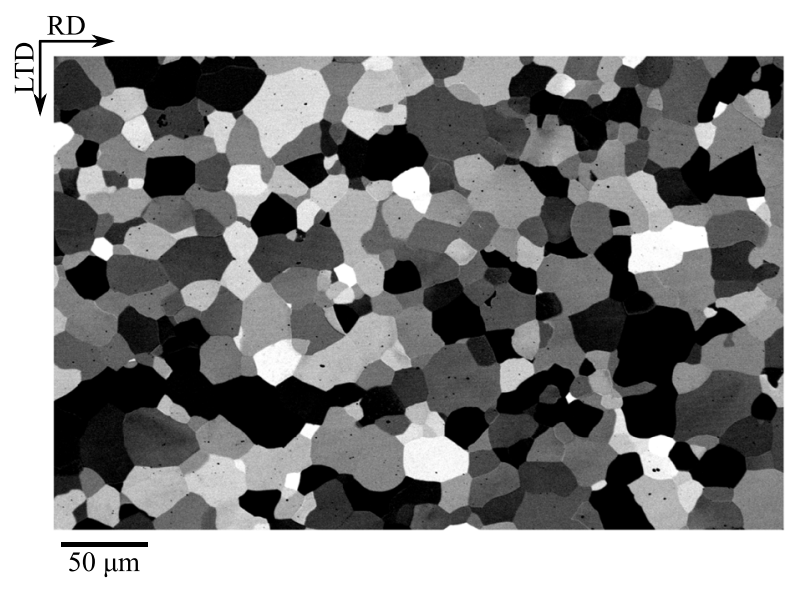

(a)

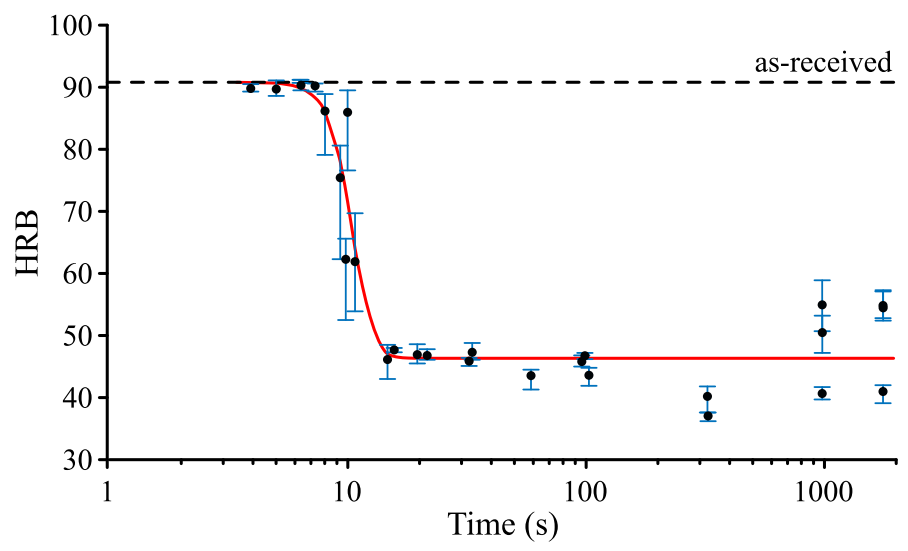

(b)

Fig. 3- (a) A typical recrystallized, undeformed microstructure is shown in a BSE image. (b) The variation in Rockwell B hardness (HRB) with the logarithm of annealing time at $850^{\circ} \mathrm{C}$ in a salt pot demonstrates that recrystallization is complete in less then $30 \mathrm{~s}$. 


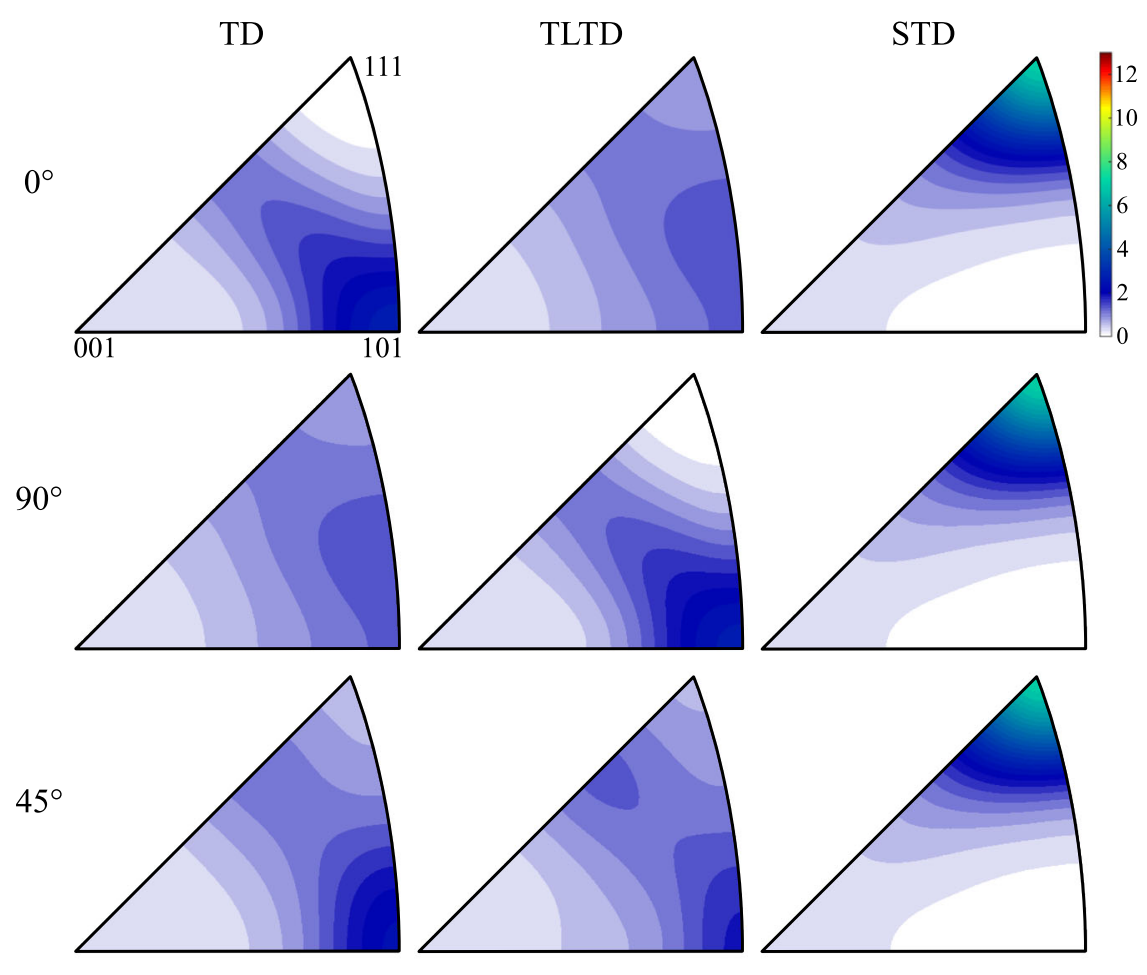

(a)
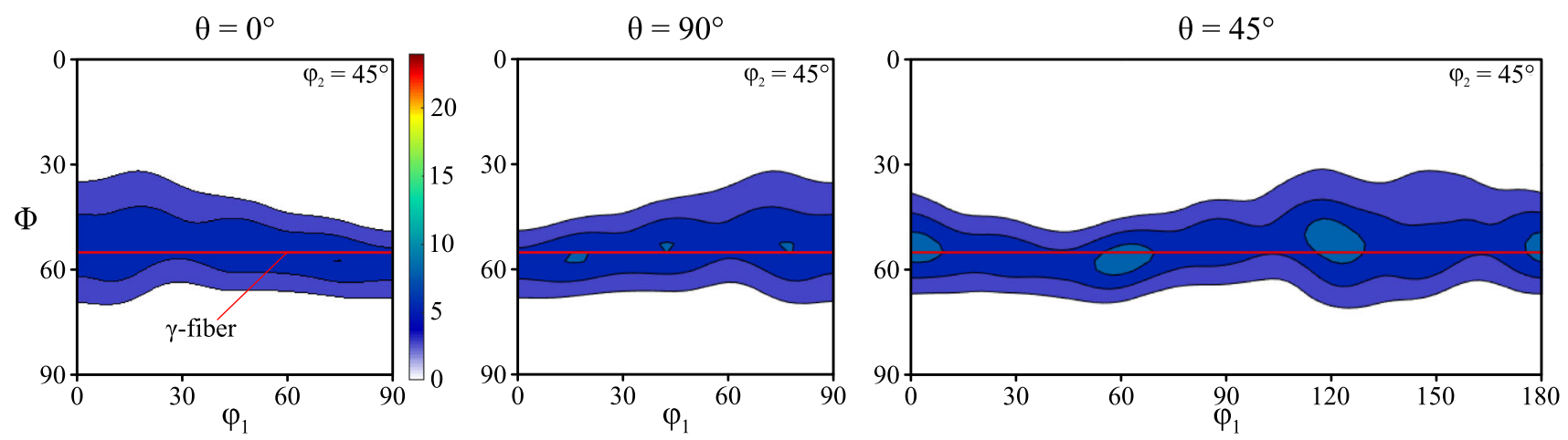

(b)

Fig. 4-(a) Inverse pole figures are shown from the recrystallized material (annealed at $850^{\circ} \mathrm{C}$ for 30 min.) for three different specimen orientations relative to the sheet rolling direction. Data are referenced to the tensile direction (TD), tensile long-transverse direction (TLTD), and short-transverse direction (STD). (b) ODFs of the recrystallized material are shown on $\varphi_{2}=45$ deg slices from Euler space for the three different tensile specimen orientations. The tensile specimen reference frame defines the reference orientations for these diagrams.

EBSD data were acquired from specimens tested in tension at room temperature to true strains of $\epsilon=0.1$ and 0.2 for all three specimen orientations. These EBSD data were used to generate an ODF for each tested condition. The resulting ODFs are presented in $\varphi_{2}=$ $45 \mathrm{deg}$ slices from Euler space in Figure 6(a) relative to the tensile specimen frame. These Euler maps are presented for $\epsilon=0.1$ along the top row and for $\epsilon=$ 0.2 along the bottom row, with one column for each specimen orientation. Each specimen orientation demonstrates an increasing $\alpha$-fiber intensity with increasing strain. Note that the $\alpha$-fiber is relative to the tensile specimen frame. These data demonstrate the utility of presenting data relative to the specimen frame instead of the frame of the original rolled sheet. The increase in intensity of the $\alpha$-fiber for each specimen orientation is an effect expected from lattice rotation.

VPSC simulations were conducted primarily to confirm that the results presented in Figure 6(a) can be reasonably attributed to lattice rotation. The VPSC simulations take into account only lattice rotation. Results from these simulations are presented in Figure $6(\mathrm{~b})$ at true strains of $\epsilon=0.1$ and 0.2 for each of the three specimen orientations. The input data for original grain sizes and orientations were taken from EBSD data of the recrystallized IF steel, rotated appropriately corresponding with each specimen orientation. VPSC outputs were used to produce the ODFs presented in Figure 6(b) as Euler maps for $\varphi_{2}=45 \mathrm{deg}$. The results of VPSC predictions in Figure $6(\mathrm{~b})$ and the 


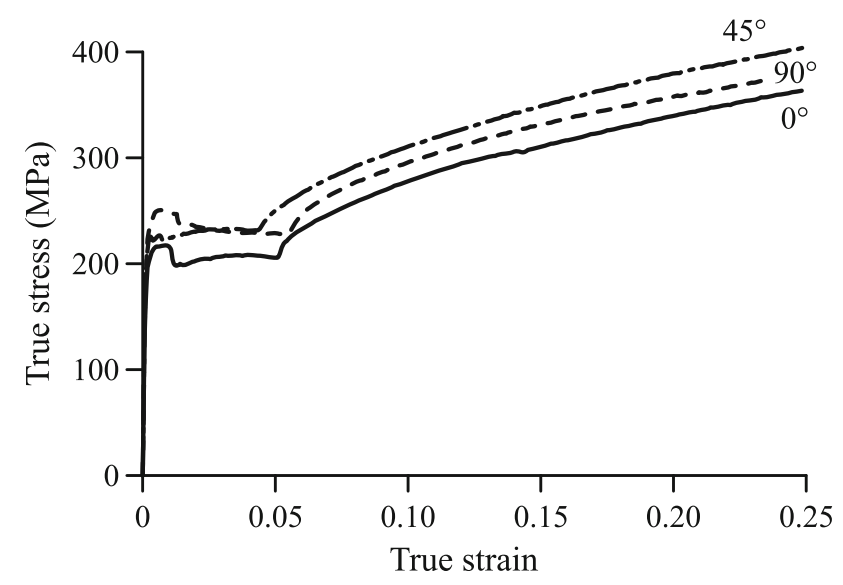

Fig. 5-Tensile data obtained at room temperature from the recrystallized material for three different tensile specimen orientations relative to the sheet rolling direction are presented as true stress $v s$ true strain.

experimental results of (a) are presented with the same intensity scaling. The VPSC simulations predict a higher intensity of the $\alpha$-fiber component created by deformation than is observed in the experimental data. But, the general change in texture from crystal rotation predicted by the VPSC simulations is otherwise very similar to that observed from experiment. This is interpreted as confirmation that texture changes from room-temperature deformation are primarily the result of lattice rotation.

\section{Elevated-Temperature Tensile Data}

Data from tensile tests conducted at a true-strain rate of $\dot{\epsilon}=10^{-4} \mathrm{~s}^{-1}$ and temperatures of 750,800 , and $850^{\circ} \mathrm{C}$ for specimens in the $\theta=0 \mathrm{deg}$ orientation are presented in Figure 7(a) as true stress plotted against true strain. A steady flow stress is achieved quickly at $850^{\circ} \mathrm{C}$ and is thereafter constant, indicating that deformation is by steady-state creep up to $\epsilon \approx 0.2$. At the two lower temperatures, the flow stress achieved is only slightly less steady. Figure 7(b) presents data for steady-state flow stress as a function of true-strain rate, on dual-logarithmic scales, for temperatures from 840 to $890{ }^{\circ} \mathrm{C}$. The slope of these data is equal to the strain-rate sensitivity. These data indicate a strain-rate sensitivity of approximately $m=0.2$, or equivalently a stress exponent of $n=m^{-1}=5$. This suggests that deformation is by dislocation-climb-controlled creep, also known as five-power creep, as is expected for steady-state creep of BCC metals. ${ }^{[3-39]}$

EBSD data were acquired from tensile specimens tested at $850^{\circ} \mathrm{C}$. Figure 8 presents EBSD data as IPF maps with respect to the specimen TD for specimens tested to true strains of $\epsilon=0.1$ (left column) and 0.2 (right column) for each specimen orientation, with a unique specimen orientation shown on each row. All images are at the same magnification. Subgrains are evident in several grains, as shown by slight orientation changes (mapped as color changes) within individual grains. Subgrain boundaries are quite distinct, as is expected from creep deformation of a material with a high stacking-fault energy. ${ }^{[35,37-40]}$ Microstructural data from specimens tested in the vacuum furnace, not shown here, exhibited grain sizes indistinguishable from those of the quenched specimens but with far fewer subgrains evident; the slow cooling in the vacuum furnace preserved fewer subgrains but did not alter grain sizes. Because the grain sizes observed from quenched and furnace-cooled specimens were indistinguishable, both types of tested specimens were used for grain size measurements.

Figure 9 presents ODFs as $\varphi_{2}=45 \mathrm{deg}$ slices from Euler space for the specimens tensile tested at $850^{\circ} \mathrm{C}$. These ODFs were constructed from EBSD data for each specimen orientation at true strains of (top row) $\epsilon=0.1$ and (bottom row) $\epsilon=0.2$, and the data are presented with respect to the tensile specimen frame. The crystallographic textures produced by deformation at elevated temperature, Figure 9, are notably different from those produced by deformation at room temperature, Figure 6(a). Deformation at elevated temperature produces an increase of the $\alpha$-fiber component that is less sharp than that produced by deformation at room temperature. Deformation at elevated temperature retains the strong $\gamma$-fiber component of the recrystallization texture, Figure 4, that is lost by deformation at room temperature for the larger strain of $\epsilon=0.2$, also shown in Figure 6.

\section{Grain Size Measurements}

Lineal-intercept grain sizes measured from SEM-BSE images are reported in Figure 10 as a function of the logarithm of time at $850^{\circ} \mathrm{C}$. The recrystallized grain size of $\bar{d}_{R X}=13 \pm 1 \mu \mathrm{m}$ was unchanged by static annealing for $100 \mathrm{~min}$. at $850^{\circ} \mathrm{C}$. Static grain growth was observed only at the long annealing time of $480 \mathrm{~min}$. ( $8 \mathrm{hrs}$.), which increased the grain size to $21 \pm 2 \mu \mathrm{m}$. Dynamic grain growth produced significant grain size increases for total times at temperature of $100 \mathrm{~min}$. and less. Tensile straining to $\epsilon=0.1$, for which the specimen was at $850{ }^{\circ} \mathrm{C}$ for a total time of $80 \mathrm{~min}$. $(60 \mathrm{~min}$. soak plus 20 min. of deformation), produced a grain size of $19 \pm 1 \mu \mathrm{m}$, which is approximately the same as that produced by static grain growth for $480 \mathrm{~min}$. Tensile straining to $\epsilon=0.2$, which required the specimen to be at $850^{\circ} \mathrm{C}$ for a total time of $100 \mathrm{~min}$. (60 min. soak plus $40 \mathrm{~min}$. of deformation), produced a grain size of $32 \pm 3 \mu \mathrm{m}$, more than doubling the original grain size.

Figure 11 presents distributions of grain size, reported as lineal-intercept grain diameter, measured from EBSD data for each tensile specimen orientation at true strains of $\epsilon=0$ (as recrystallized), 0.1 , and 0.2 . It is quite important to note that grain sizes measured from EBSD data are often smaller than those measured by optical microscopy or SEM techniques. ${ }^{[41]}$ This is because of EBSD's ability to identify grain boundaries that are not identified using other characterization techniques. Thus, the values of grain size reported in Figure 10, measured using SEM-BSE images, cannot be interchanged with those reported in Figure 11, measured using EBSD 

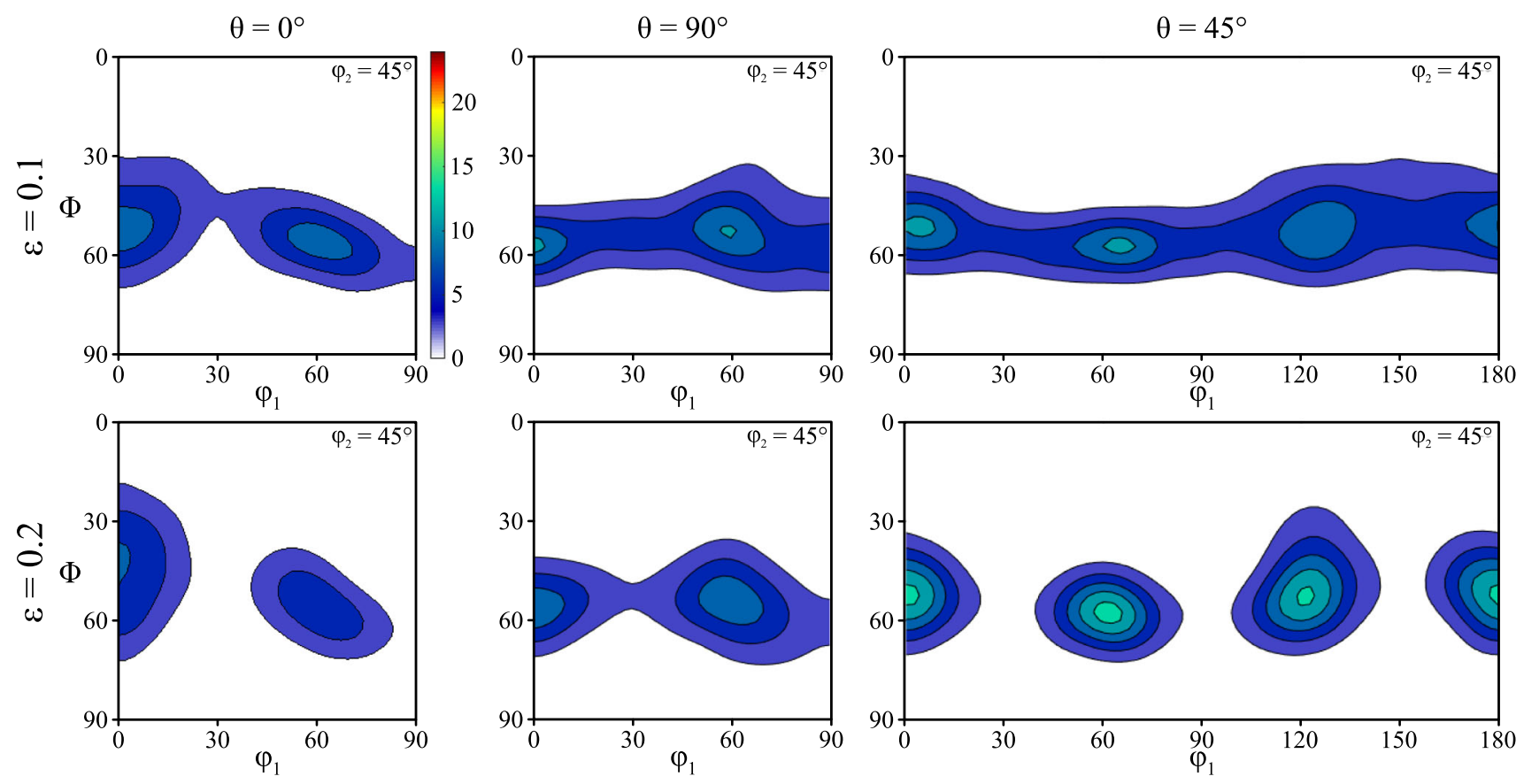

(a) Experiment
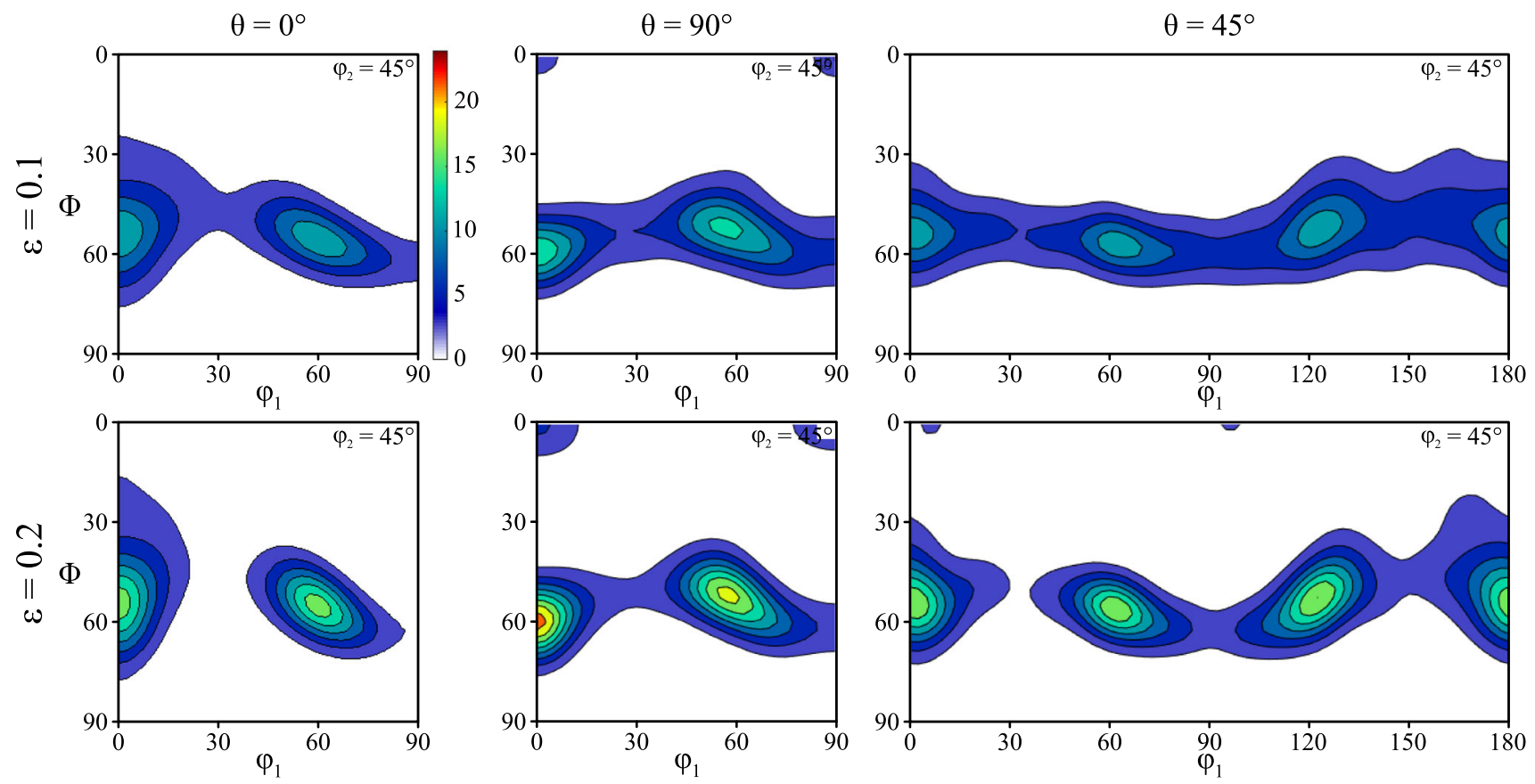

(b) VPSC predictions

Fig. 6- (a) ODFs from the recrystallized material after tensile testing at room temperature to true strains of $\epsilon=0.1$ and 0.2 in three different specimen orientations are presented on $\varphi_{2}=45 \mathrm{deg}$ slices from Euler space. All data are identically scaled. (b) Deformation textures predicted by VPSC simulations are presented for conditions identical to those of the experimental data in (a) and with identical scaling.

data. Shown with each grain size distribution of Figure 11 are the number of grains observed, $N$, and the average lineal-intercept grain diameter, $\bar{\ell}$, of the entire distribution. Each distribution was fit with either a single $(\epsilon=0)$ or a double $(\epsilon=0.1$ and 0.2$)$ log-normal distribution, and a curve is shown for each fit. The fitted values for statistical measures of each grain size distribution are reported in Table III. The form for the 


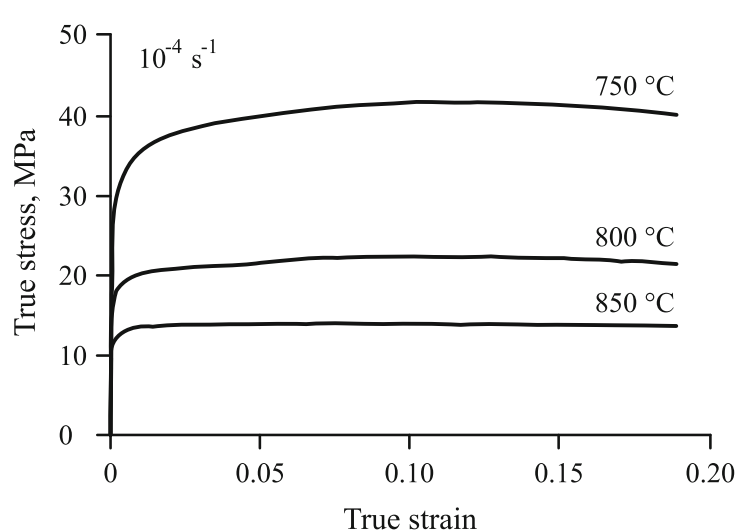

(a)

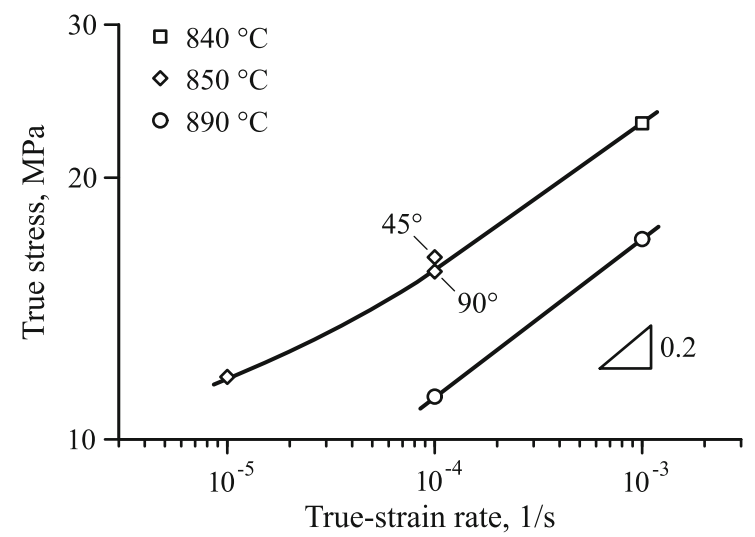

(b)

Fig. 7-(a) True stress is plotted against true strain for specimens tested in vacuum with $\theta=0$ deg at $\dot{\epsilon}=10^{-4} \mathrm{~s}^{-1}$ and temperatures of 750,800 , and $850^{\circ} \mathrm{C}$. (b) The steady-state true flow stress is plotted against the true-strain rate on dual-logarithmic scales for data from tension tests at elevated temperatures in vacuum. Except where otherwise indicated, data are from specimens with the $\theta=0$ deg orientation.
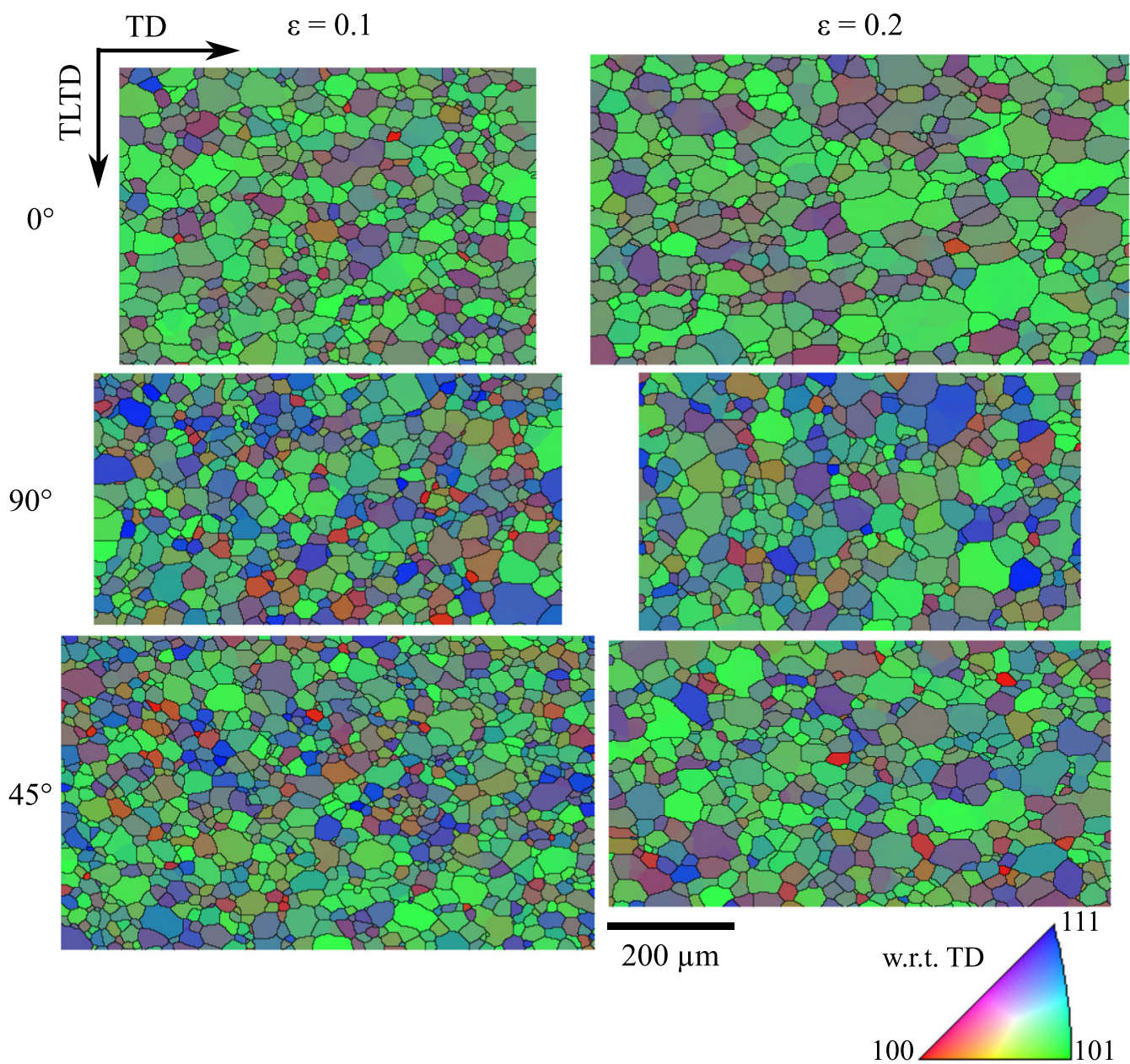

Fig. 8-EBSD data are presented as IPF maps relative to the TD for specimens tested in tension at $850^{\circ} \mathrm{C}$ and $10^{-4} \mathrm{~s}^{-1}$ to true strains of $\epsilon=$ 0.1 and 0.2 in air and water quenched, with three different orientations of the TD relative to the RD. All images are at the same magnification. 

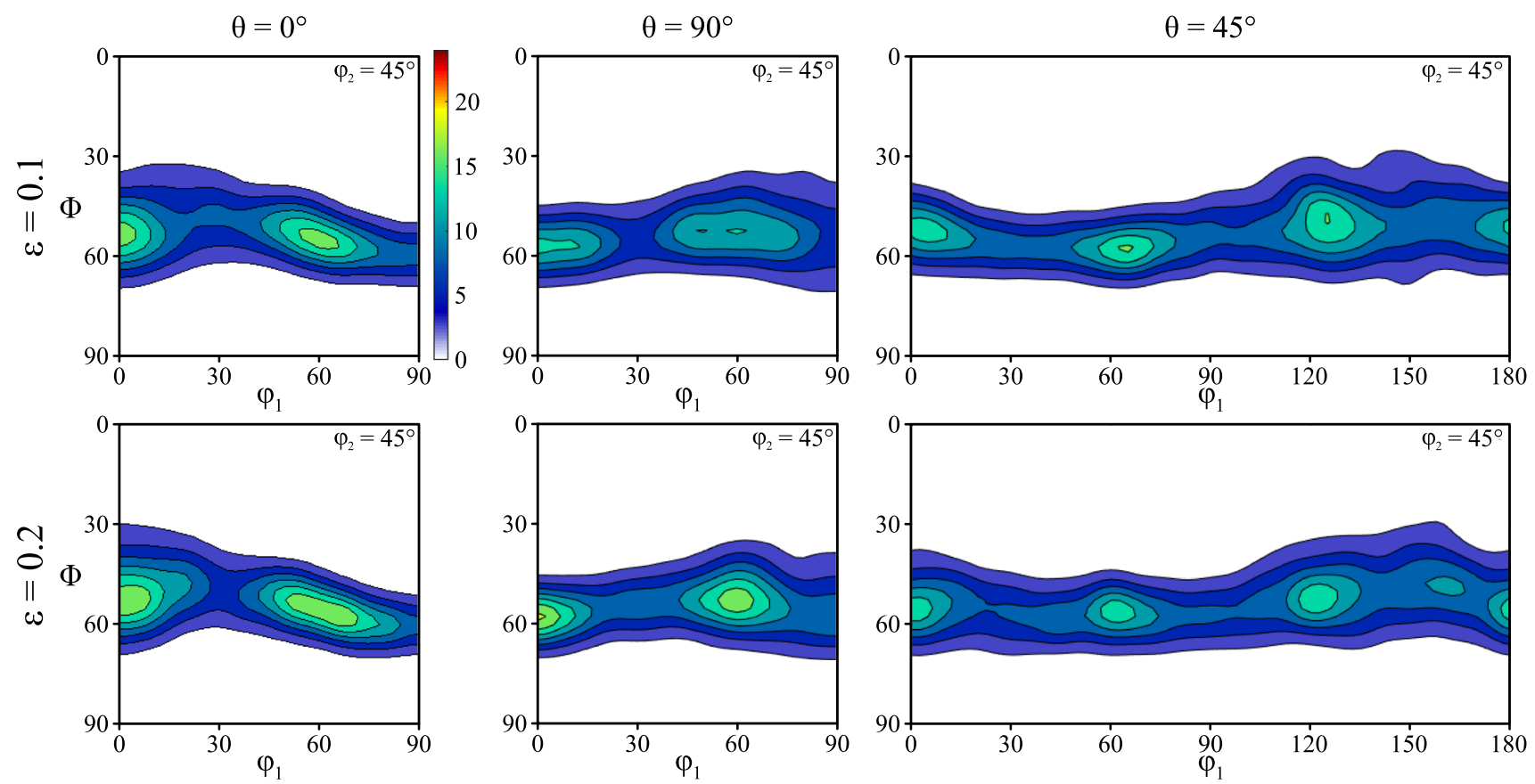

Fig. 9- ODFs of the recrystallized material tensile tested at $850^{\circ} \mathrm{C}$ and $10^{-4} \mathrm{~s}^{-1}$ to true strains of $\epsilon=0.1$ and 0.2 in three different TD orientations are presented on $\varphi_{2}=45 \mathrm{deg}$ slices from Euler space. All data are identically scaled.

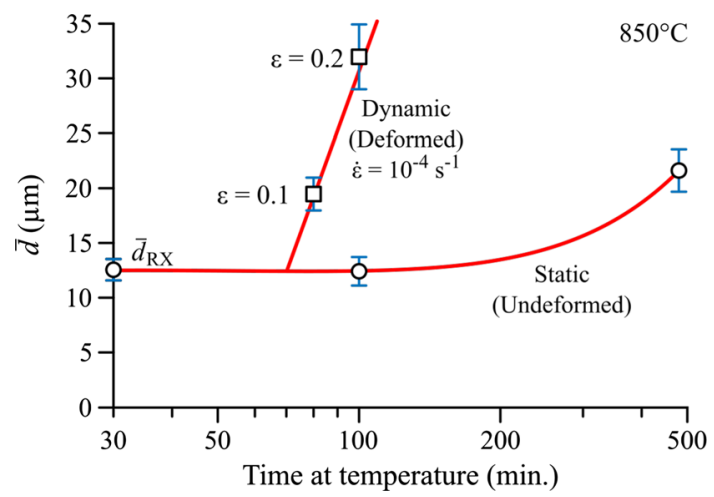

Fig. 10-Average lineal-intercept grain size, $\bar{d}$ measured from BSE images, is presented as a function of the logarithm of time at a temperature of $850^{\circ} \mathrm{C}$ for several different test conditions. Deformed specimens were tested in the $\theta=0$ deg orientation.

probability distribution function, PDF, used in fitting is,

$$
\begin{aligned}
\mathrm{PDF}= & \frac{1}{\ell\left(\mathrm{SD}_{p}\right) \sqrt{2 \pi}} \exp \left(-\frac{\left(\ln \ell-\mu_{p}\right)^{2}}{2\left(\mathrm{SD}_{p}\right)^{2}}\right) \\
& +\frac{1}{\ell\left(\mathrm{SD}_{s}\right) \sqrt{2 \pi}} \exp \left(-\frac{\left(\ln \ell-\mu_{s}\right)^{2}}{2\left(\mathrm{SD}_{s}\right)^{2}}\right),
\end{aligned}
$$

where $\ell$ is lineal-intercept grain diameter measure of grain size, $\mu$ is the expected value for the natural logarithm of grain size, SD is the standard deviation of the natural logarithm of grain size, and the subscripts $p$ and $s$ denote the primary and secondary distributions, respectively. The secondary distribution, the second term of Eq. [1], was fit to the smallest grain sizes, and it consistently contained the smallest number of grains between the two distributions. Table III presents the number fraction of grains belonging to the primary distribution as $f_{p}$, and the number fraction belonging to the secondary distribution is $100 \mathrm{pct}-f_{p}$. Because of the small number of grains within the secondary distributions, the values of $\mathrm{SD}_{s}$ were constrained during numerical fitting. The constrained value used, $\mathrm{SD}_{s} \approx 0.3$, was determined to be reasonable through a process of iterative fitting.

\section{DISCUSSION}

\section{A. Plastic Flow Behaviors}

The plastic flow of the recrystallized IF steel at room temperature, shown in Figure 5, demonstrates two behaviors worth noting: (1) discontinuous yielding and (2) a small difference in strength with tensile axis orientation. A modest yield-point phenomenon and Lüders region occur despite a low $\mathrm{C}+\mathrm{N}$ concentration, approximately 0.0049 wt. pct. or 49 ppm by weight, and the Ti addition. Ti scavenges both $\mathrm{N}$ and $\mathrm{C}$ because it is a strong nitride (TiN) former and forms titanium carbosulfides. ${ }^{[1]}$ A possible reason for this discontinuous yielding behavior is the annealing temperature of $850{ }^{\circ} \mathrm{C}$ used for recrystallization, which is higher than the upper limit of $720^{\circ} \mathrm{C}$ recommended for box annealing of similar steels in industrial practice. ${ }^{[3]}$ Takaki et al. reported the onset of discontinuous yielding in steels with low-carbon concentrations, as low as $17 \mathrm{ppm} \mathrm{C}$, after recrystallization to small grain sizes. ${ }^{[42]}$ This effect was attributed to a large difference between the dislocation friction stress, which is primarily a function of alloy content, and the yield stress, which is elevated by 


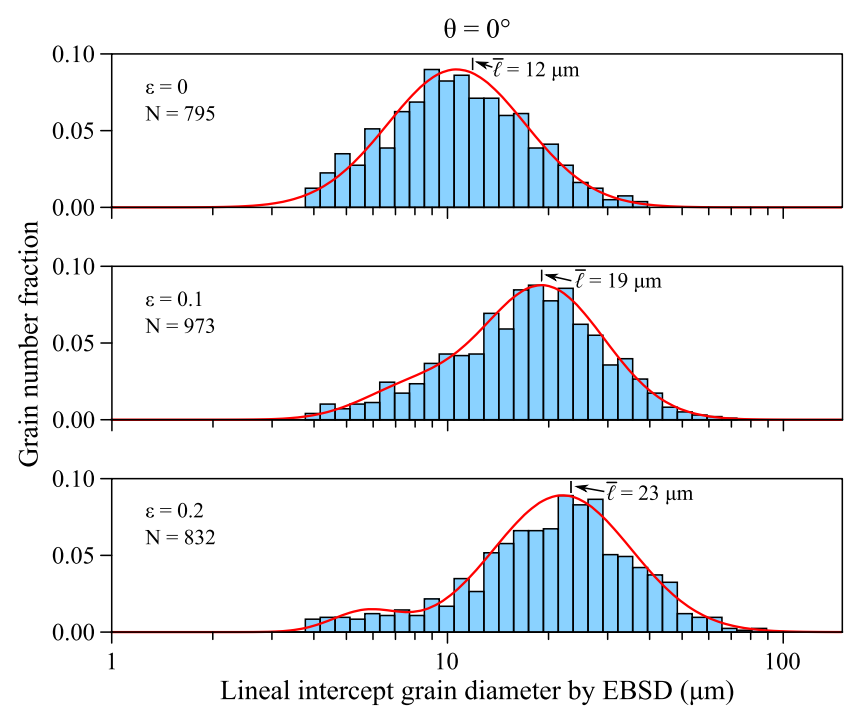

(a)

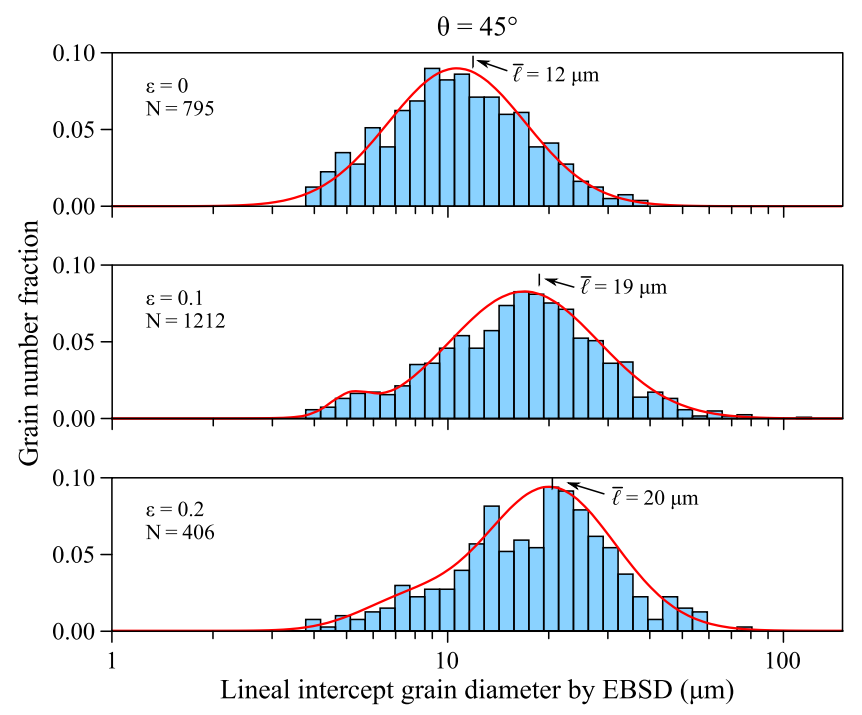

(c)

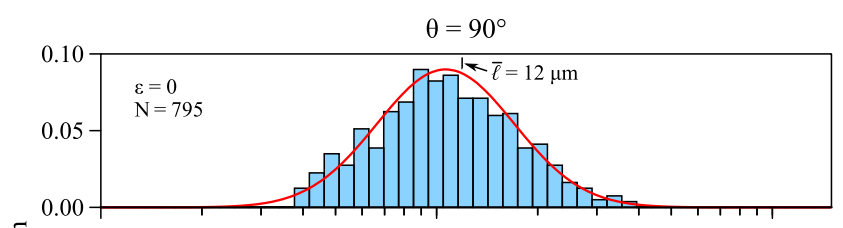

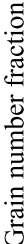
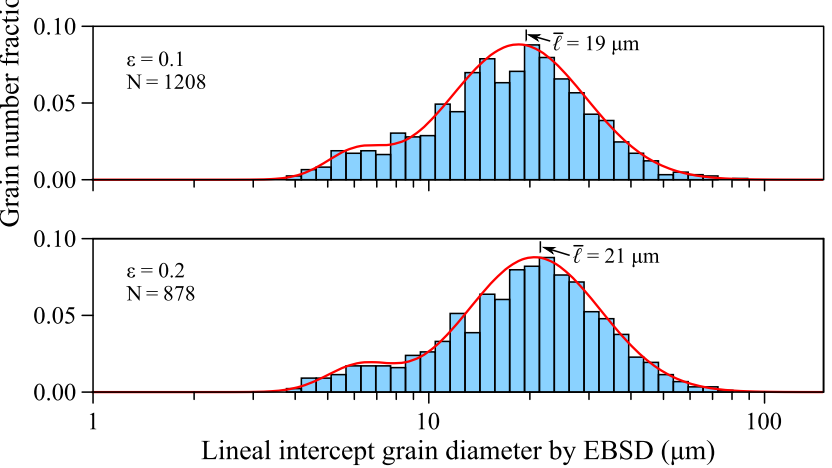

(b)

Fig. 11-Grain diameter distributions are shown for specimens tested at $850^{\circ} \mathrm{C}$ and $10^{-4} \mathrm{~s}^{-1}$ to true strains of $\epsilon=0$ (recrystallized material), 0.1 , and 0.2 with TD orientations of $(a) \theta=0 \mathrm{deg},(b) 90 \mathrm{deg}$, and $(c) 45 \mathrm{deg}$ relative to the RD. Grain sizes are shown as lineal-intercept grain diameter calculated from EBSD data.

the Hall-Petch effect at fine grain sizes. Takaki et al. suggested that yielding is caused by dislocation emission from grain boundaries. They observed a strong segregation of $\mathrm{C}$ to grain boundaries, where the interstitial $\mathrm{C}$ atoms can stabilize dislocation sources at grain boundaries to produce discontinuous yielding. By this mechanism, even very small concentrations of $\mathrm{C}$ in solution can segregate to grain boundaries and induce discontinuous yielding. The annealing temperature and time used for recrystallization of the IF steel, $850{ }^{\circ} \mathrm{C}$ for 30 min., may have produced just this effect. Takaki et al. observed that $\mathrm{N}$ is much less likely to segregate to grain boundaries and, thus, is unlikely to play a role in the discontinuous yielding observed.

Figure 5 demonstrates only slight differences in room-temperature yield strength and flow stress between different tensile specimen orientations. The maximum differences in yield strength with specimen orientation are $16 \mathrm{pct}$ for the upper yield point and $11 \mathrm{pct}$ for the lower yield point. The 0 deg specimen orientation presents the lowest yield strengths and the lowest flow stresses following yielding. Relaxed constraint predictions presented by Ray et al. for specific texture components of the strong $\gamma$-fiber evident in the recrystallization texture of the IF steel indicate very little in-plane yield stress anisotropy ${ }^{[3]}$ Similarly, the VPSC predictions of the present study indicate little difference (less than $7 \mathrm{pct}$ ) in flow stress with tensile direction within the sheet plane. Thus, it is not clear if the slight differences in yield strength and flow stress between the three specimen orientations are caused by the recrystallization texture or other factors, such as 
microstructural differences created during recrystallization annealing. The differences in flow stress with tensile specimen orientation at $850^{\circ} \mathrm{C}$ are even less significant and are likely within measurement uncertainty.

The tensile data obtained at elevated temperatures and presented in Figure 7 suggest deformation by the five-power creep mechanism, also termed dislocation climb controlled creep. ${ }^{[35,43]}$ The EBSD data from quenched specimens demonstrate subgrain formation, which is consistent with this mechanism. The phenomenological equation for five-power creep predicts the following ${ }^{[35,43]}$.

$$
\dot{\varepsilon}=A D\left(\frac{\sigma}{E}\right)^{n}
$$

where $\dot{\varepsilon}$ is true-strain rate or steady-state creep rate; $A$ is a material-dependent constant; $D$ is the lattice self-diffusion coefficient; $\sigma$ is steady-state flow stress; $E$ is the unrelaxed, dynamic, temperature-dependent elastic modulus; and $n$ is the stress exponent, which should be $n \approx 5$. To test this mechanism hypothesis, plastic flow stress data for the IF steel at temperatures from 750 to $890^{\circ} \mathrm{C}$ are plotted as $\dot{\epsilon} / D$ against $\sigma / E$ on dual-logarithmic scales in Figure 12. Particular care must be taken with the values of diffusion coefficient and elastic modulus used to construct this plot. Both exhibit highly nonlinear behaviors in $\alpha-\mathrm{Fe}$ below the Curie temperature, $T_{\mathrm{C}}=770{ }^{\circ} \mathrm{C}(1043 \mathrm{~K})$. The unrelaxed, dynamic, temperature-dependent elastic modulus for $\alpha$-Fe was taken from Köster. ${ }^{[44]}$ Values for the lattice self-diffusion coefficient as a function of temperature were taken from those recommended by Oikawa. ${ }^{[45]}$ The compensated data for the IF steel fall reasonably well onto a single line with a slope of $n \approx 5$ in Figure 12 . The slope of data on this plot is equal to the stress exponent, and linear regression produced a value of $n=4.7$ for the IF steel. Plotted for comparison are data reported by Sherby and Burke for low-impurity AISI Fe and $\mathrm{Fe}-0.002$ pct $\mathrm{C}$ at temperatures from $749^{\circ} \mathrm{C}$ to $889^{\circ} \mathrm{C} .^{[35]}$ Data for each of these fall onto a separate line of similar slope. Comparison between these materials indicate increasing flow resistance with increasing alloy content for a constant value of $\dot{\epsilon} / D$. These results are consistent with the hypothesis of deformation governed by five-power creep.

\section{B. Dynamic Grain Growth}

The IF steel recrystallized at $850{ }^{\circ} \mathrm{C}$ to a fine grain size of $\bar{d}_{\mathrm{RX}}=13 \mu \mathrm{m}$, as measured from BSE images using the lineal-intercept technique. This grain size remained constant under static annealing for up to at least $100 \mathrm{~min}$. However, the grains grew by 46 pet to $19 \mu \mathrm{m}$ under tensile straining to $\epsilon=0.1$ at $850{ }^{\circ} \mathrm{C}$ and $10^{-4} \mathrm{~s}^{-1}$. Of the approximately $80 \mathrm{~min}$. total time at $850^{\circ} \mathrm{C}$ for this experiment, plastic deformation and the associated dynamic grain growth occurred during only the last 17 min. of testing. Static annealing required approximately $500 \mathrm{~min}$. to achieve a similar degree of grain growth, as shown in Figure 10. These data demonstrate the very significant acceleration of grain growth by plastic deformation at temperature. Tensile straining to $\epsilon=0.2$ at $850^{\circ} \mathrm{C}$ and $10^{-4} \mathrm{~s}^{-1}$ imposed plastic deformation for only the last $33 \mathrm{~min}$. of an approximately $100 \mathrm{~min}$. time at temperature, yet produced a $146 \mathrm{pct}$ increase in grain size to $32 \mu \mathrm{m}$.

It is worth noting again that grain sizes measured from EBSD data are not directly equivalent to those measured by other techniques. ${ }^{[41]}$ Because EBSD data allow detection of boundaries that other observation techniques may miss, grain sizes measured by EBSD are typically the smaller measure. This is the reason that the average grain sizes measured from EBSD data, reported as $\bar{\ell}$ in Table III and Figure 11, are smaller than those measured from BSE images, reported as $\bar{d}$ in Figure 10. The grain sizes measured from BSE images are up to 37 pct larger than those measured from EBSD data. The EBSD data were used to measure the aspect ratios of individual grains. The average grain aspect ratio for each test condition is reported in Table III. The numerical technique used for this calculation fit to each grain an ellipse with the same area as the grain and calculated the aspect ratio as the ratio of the ellipse major to minor axes. ${ }^{[31,46]}$ The average grain aspect ratio varied from 1.4 to 1.5 for all test conditions, as reported in Table III. Considering this measure, the calculation technique behind it, and qualitative observations of microstructure images, the grains for all test conditions are interpreted as approximately equiaxed.

The EBSD technique offers a significant advantage over other techniques for measuring grain size. Because grains are individually segmented, statistical measures of grain populations are readily made. This advantage is demonstrated by the grain diameter histograms shown in Figure 11. The recrystallized grain diameter data were fit quite well by a log-normal distribution, as expected. ${ }^{[8]}$ Dynamic grain growth, however, produced grain diameter distributions that deviated from a simple log-normal distribution. This was interpreted to result from two populations of grains, one population that grew rapidly by dynamic grain growth and a second that grew slowly or not at all. In line with this interpretation, a linear combination of two log-normal distributions was fit to each grain diameter dataset from specimens plastically strained at $850^{\circ} \mathrm{C}$, as described by Eq. [1] and with fitting results reported in Table III. The mean of each primary distribution increased with plastic strain for all test conditions, and the standard deviation of each primary distribution remained approximately equal to that of the recrystallized microstructure. This is exactly the theoretical expectation for normal grain growth. ${ }^{[8]}$ Each secondary distribution, however, had a smaller mean that changed little with strain; changes in the means of the secondary distributions with strain are less than the uncertainty expected from measurements and numerical fitting. The populations of small grains described by the secondary distributions deviate from the theoretical expectation for normal grain growth. Each secondary distribution covered too small a population of grains to unequivocally determine changes in population size with strain. However, the fraction of grains associated with the secondary population, (1 - 
Table III. Statistics for Lineal-Intercept Grain Diameter Distributions Measured from EBSD Data for Specimens Tested at $850^{\circ} \mathrm{C}$ and $10^{-4} \mathrm{~s}^{-1}$

\begin{tabular}{llcccccccccc}
\hline$\theta$ & $\epsilon$ & $N$ & $\bar{\ell}(\mu \mathrm{m})$ & $\mathrm{GAR}$ & $\mu_{p}$ & $\mathrm{SD}_{p}$ & $f_{p}(\mathrm{pct})$ & $\mu_{s}$ & $\mathrm{SD}_{s}$ & $\ell_{p}(\mu \mathrm{m})$ & $\ell_{s}(\mu \mathrm{m})$ \\
\hline All & 0 & 795 & 11.9 & 1.5 & 2.4 & 0.5 & 100 & - & - & 11 \\
$0 \mathrm{deg}$ & 0.1 & 973 & 19.1 & 1.5 & 2.9 & 0.5 & 85 & 2.1 & 0.3 & 18 \\
$0 \mathrm{deg}$ & 0.2 & 832 & 23.3 & 1.5 & 3.1 & 0.5 & 93 & 1.8 & 0.3 & 21 & 8 \\
$90 \mathrm{deg}$ & 0.1 & 1208 & 19.5 & 1.4 & 2.9 & 0.5 & 92 & 1.8 & 0.3 & 18 & 6 \\
$90 \mathrm{deg}$ & 0.2 & 878 & 21.5 & 1.4 & 3.0 & 0.4 & 92 & 1.8 & 0.3 & 20 & 6 \\
$45 \mathrm{deg}$ & 0.1 & 1212 & 18.7 & 1.4 & 2.8 & 0.5 & 96 & 1.6 & 0.3 & 16 & 5 \\
$45 \mathrm{deg}$ & 0.2 & 406 & 20.5 & 1.4 & 3.0 & 0.5 & 88 & 1.9 & 0.3 & 20 \\
\hline
\end{tabular}

$\theta$ : TD orientation relative to $\mathrm{RD}$.

$\epsilon$ : True strain applied.

$N$ : Number of grains measured.

$\bar{\ell}:$ Mean lineal-intercept grain diameter in $\mu \mathrm{m}$ from EBSD data.

GAR : Mean grain aspect ratio.

$\mu_{p}$ : Mean from the primary log-normal distribution in $\ln (\mu \mathrm{m})$.

$\mathrm{SD}_{p}$ : Standard deviation from the primary log-normal distribution in $\ln (\mu \mathrm{m})$.

$f_{p}$ : Fraction of grains in the primary log-normal distribution.

$\mu_{s}$ : Mean from the secondary log-normal distribution in $\ln (\mu \mathrm{m})$.

$\mathrm{SD}_{s}$ : Standard deviation from the secondary log-normal distribution in $\ln (\mu \mathrm{m})$.

$\ell_{p}$ : Lineal-intercept grain diameter at the mean of the primary distribution.

$\ell_{s}$ : Lineal-intercept grain diameter at the mean of the secondary distribution.

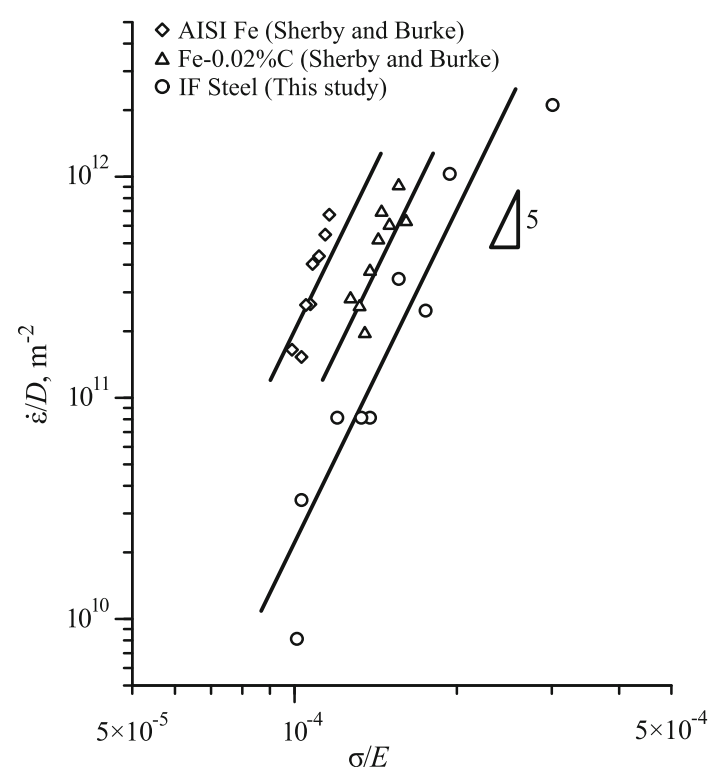

Fig. 12-Data are plotted on dual-logarithmic scales as true-strain rate normalized by the lattice self-diffusion coefficient for $\alpha$-iron against flow stress normalized by the unrelaxed, dynamic, temperature-dependent elastic modulus. Data are presented for AISI $\mathrm{Fe}$ and $\mathrm{Fe}-0.02 \mathrm{pctC}$, both from Sherby and Burke, ${ }^{[35]}$ and for the IF steel of this study.

$f_{p}$ ) from Table III, either decreased or remained constant with strain for the $\theta=0$ and $90 \mathrm{deg}$ specimen orientations. The apparent increase in the grain fraction associated with the secondary population for the $\theta=$ $45 \mathrm{deg}$ specimen orientation between strains of 0.1 and 0.2 is most likely an artifact of the relatively small number of grains measured from the $\epsilon=0.2$ condition in this orientation. Based on this interpretation, it is hypothesized that a group of small grains comprise a small, secondary grain population that is resistant to dynamic grain growth. It is further hypothesized that grains from this secondary population are gradually consumed by dynamic grain growth in the primary population of larger grains. Determining why the small secondary population of grains is resistant to dynamic growth is beyond the scope of the present investigation but would certainly be of interest for future study. Because the secondary population of grains is a small fraction of the total grain population, 15 pct or less, and because no large grains that might be considered abnormal were observed, the growth behavior observed is categorized as dynamic normal grain growth, but with the caveats noted above.

Dynamic grain growth has been studied only infrequently outside the field of superplastic materials. However, there are some notable examples beyond superplastic materials. Okayasu, Fukutomi and coworkers investigated dynamic grain growth in $\mathrm{Al}-\mathrm{Mg}$ and Al-Cu binary solid-solution alloys ${ }^{[13,14]}$ and in Fe-3 pct $\mathrm{Si}^{[15]}$ Another is recent work on dynamic abnormal grain growth in the BCC refractory metals $\mathrm{Mo}^{[16,18-22]}$ and Ta. ${ }^{[17]}$ Investigations of superplasticity are particularly interested in dynamic grain growth because the grain boundary-sliding deformation mechanism responsible for the majority of superplastic behavior is very sensitive to grain size ${ }^{[47-49]}$ Grain growth during superplastic deformation will increase flow resistance and can transition deformation into a non-superplastic regime. Both phenomenological analyses and models have been applied to dynamic grain growth during superplastic deformation. ${ }^{[9-11]}$ These typically result in a relationship for grain size that is a function of strain, with a linear relationship being the simplest and most common, such as $^{[9,10]}$,

$$
d=d_{0}+\beta \varepsilon,
$$

where $d_{0}$ is the original recrystallized grain size, $\beta$ is the growth rate with strain, and $\varepsilon$ is true strain. A necessary condition for superplastic deformation is a low stress exponent of $n \leq 2$. The deformation of the IF steel is 
clearly not superplastic because it does not meet this condition. Interestingly, Bate et al. observed similar dynamic grain growth characteristics between superplastic and non-superplastic deformation in two aluminum alloys. ${ }^{[11]}$ Observations of dynamic abnormal grain growth in the BCC refractory metal Mo also suggested growth to be approximately linear with strain. ${ }^{[18]}$ Based on these results, it is reasonable to attempt fitting of the simple grain growth relation in Eq. [3] to the IF steel data. Equation [3] fits the limited data for average grain size as a function of strain reasonably well. Considering only data from the $\theta=$ 0 deg orientation, grain size data from BSE images produce a growth rate of $\beta=88 \mu \mathrm{m}$, and grain sizes measured from EBSD data produce a growth rate of $\beta=60 \mu \mathrm{m}$.

\section{Crystallographic Texture Changes from Dynamic Grain Growth}

A primary goal of this investigation is to determine if dynamic grain growth produces a unique contribution to crystallographic texture and, if it does, to measure that contribution. To this end, EBSD data from the IF steel were used to produce an orientation distribution function (ODF) for each material condition studied. The categories of ODFs generated from EBSD data are as follows:

1. $\mathrm{ODF}_{\mathrm{RX}}$ for the recrystallized microstructure, as shown in Figure 4(b);

2. $\mathrm{ODF}_{\mathrm{RT}}$ for material strained in tension at room temperature, as shown in Figure 6(a); and

3. $\mathrm{ODF}_{\mathrm{HT}}$ for material strained in tension at a temperature of $850^{\circ} \mathrm{C}$ and $10^{-4} \mathrm{~s}^{-1}$, as shown in Figure 9.

A separate ODF was generated for each specimen orientation and for each true strain imposed in tension. These ODFs were used to isolate the effects of lattice rotation caused by dislocation slip and the effects of dynamic normal grain growth.

In addition to those listed above, ODFs were also produced from the results of VPSC simulations for tensile straining. The ODFs for VPSC simulation results are shown in Figure 6(b) as $\varphi_{2}=45 \mathrm{deg}$ slices from Euler space. For equivalent strains, the ODFs generated from VPSC simulation results closely match those generated from EBSD data for the specimens tested at room temperature. This is the case for all three specimen orientations. The only significant differences between the experimental ODFs and those from VPSC simulations are in peak intensity. The ODFs from VPSC simulations demonstrate more intense peaks, by a factor of approximately 1.5 , than do those from experimental data. The value of the VPSC simulations is in confirming that the differences between the textures before and after room-temperature tensile deformation are from crystal rotation by dislocation slip, the only effect predicted by the simulations. In considering the ODFs, $\mathrm{ODF}_{\mathrm{RT}}$ can be thought of as the addition of $\triangle O \mathrm{ODF}_{\mathrm{Rot}}$, the change produced by crystal rotation, to $\mathrm{ODF}_{\mathrm{RX}}$. The texture change from crystal rotation by slip was thus quantified from the ODFs using the following relationship,

$$
\Delta \mathrm{ODF}_{\mathrm{Rot}}=\mathrm{ODF}_{\mathrm{RT}}-\mathrm{ODF}_{\mathrm{RX}} .
$$

Figure 13 presents the calculated values for the $\triangle \mathrm{ODF}_{\mathrm{Rot}}$ of each tensile strain and specimen orientation as $\varphi_{2}=45 \mathrm{deg}$ slices from Euler space. The texture changes from crystal rotation are most easily understood by referencing the illustration in Figure 1 while inspecting Figure 13(a). The effects of lattice rotation are:

1. The $\alpha$-fiber texture component with respect to the tensile axis, i.e., the $\langle 110\rangle$ fiber along the TD, is strengthened for all specimen orientations. This is particularly the case for components of the $\alpha$-fiber that intersect the strong $\gamma$-fiber of the recrystallized material. This effect increases with increasing strain.

2. The (112)[1미 component of the $\alpha$-fiber, which is near an intersection of the $\alpha$-fiber with the $\gamma$-fiber, is strengthened.

3. The components of the initial $\gamma$-fiber that do not intersect the $\alpha$-fiber are weakened, particularly the $\{111\}\langle 1 \overline{2} 1\rangle$. The increase in the $\alpha$-fiber is at the expense of components within the $\gamma$-fiber.

These effects are consistent with the expectations for lattice rotation by slip during tensile straining of a BCC metal. ${ }^{[24,50]}$

In analyzing the texture produced by tensile testing at $850{ }^{\circ} \mathrm{C}$, it is important to note the mechanism responsible for deformation, five-power creep. This is a slip creep mechanism, a category of deformation mechanisms for which plastic strain is produced by dislocation slip that is rate controlled by diffusion. ${ }^{[35,43]}$ The texture changes observed from slip creep mechanisms are primarily those produced by lattice rotation during dislocation slip. ${ }^{[41]}$ This contrasts with the randomization of texture produced by deformation under grain boundary sliding, the mechanism most commonly associated with superplasticity. ${ }^{[41]}$ In the absence of dynamic grain growth, the textures produced by five-power creep in tensile tests at $850^{\circ} \mathrm{C}$ are expected to be similar to those produced by tensile deformation at room temperature, with some differences in intensity because of the diffusion-controlled relaxation processes inherent to creep deformation. The effect of lattice rotation during five-power creep was assumed to be reasonably approximated by the $\triangle O \mathrm{ODF}_{\text {Rot }}$ determined at an identical tensile strain and orientation from room-temperature tests, i.e., Eq. [4] was assumed applicable to the high-temperature tests. The effect of dynamic normal grain growth was considered to be a separate change in texture, denoted as $\triangle \mathrm{ODF}_{\mathrm{DNGG}}$. The ODF for the material after tensile deformation at high temperature was assumed to be a linear superposition of these two changes to the $\mathrm{ODF}_{\mathrm{RX}}$ for a given tensile strain and specimen orientation, as follows, 

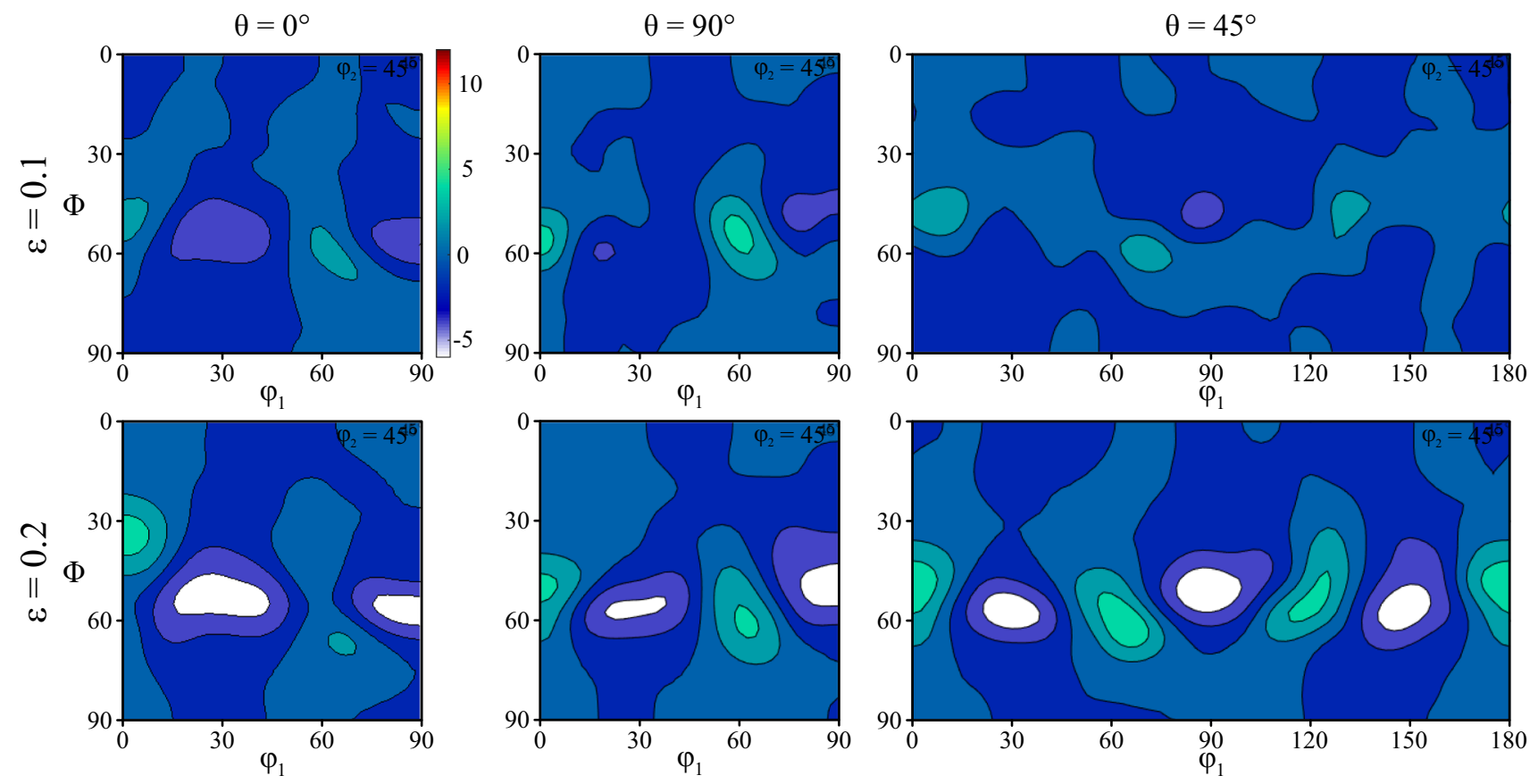

(a)
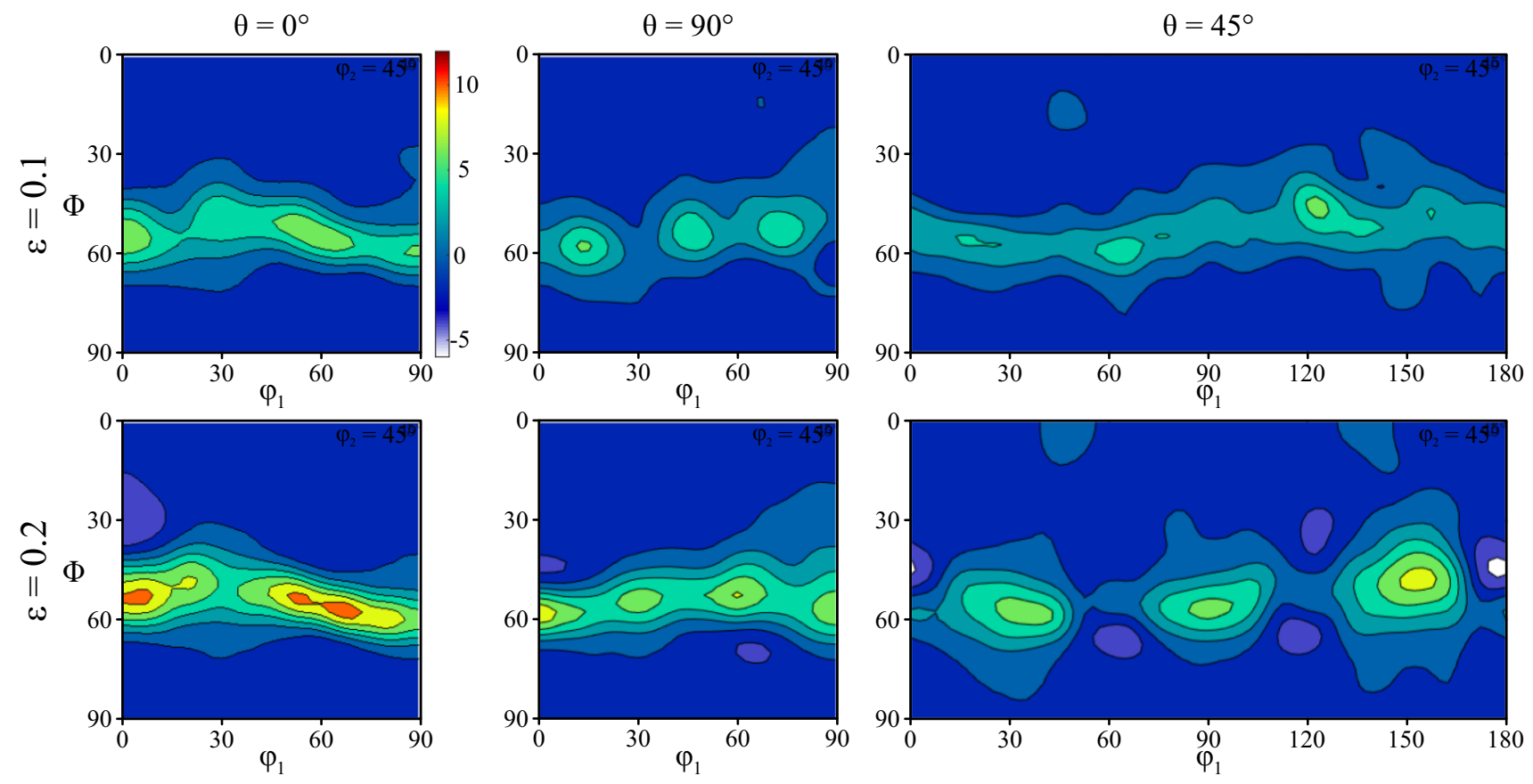

(b)

Fig. 13- ODF differences are shown as $\varphi_{2}=45 \mathrm{deg}$ slices from Euler space. (a) The $\Delta \mathrm{ODF}_{\text {Rot }}$ calculated by Eq. [4] is shown for each test condition. These results demonstrate the effect of lattice rotation during room-temperature deformation. $(b)$ The $\Delta$ ODF DNGG calculated by Eq. [6] is shown for each test condition. These results demonstrate the effect of dynamic grain growth during elevated-temperature testing.

$$
\mathrm{ODF}_{\mathrm{HT}}=\mathrm{ODF}_{\mathrm{RX}}+\Delta \mathrm{ODF}_{\mathrm{Rot}}+\Delta \mathrm{ODF}_{\mathrm{DNGG}}
$$

Applying Eq. [4] allows $\Delta \mathrm{ODF}_{\mathrm{DNGG}}$ to be calculated using only ODFs constructed from experimental data as,

$$
\Delta \mathrm{ODF}_{\mathrm{DNGG}}=\mathrm{ODF}_{\mathrm{HT}}-\mathrm{ODF}_{\mathrm{RT}}
$$

The effect of dynamic grain growth was isolated by using Eq. [6] to calculate $\Delta \mathrm{ODF}_{\mathrm{DNGG}}$ for each tensile strain and specimen orientation. The results are presented in Figure 13(b) as $\varphi=45 \mathrm{deg}$ slices of Euler space to illustrate the contribution of dynamic normal grain growth to the texture evolution in the IF steel during high-temperature tensile deformation. 
Figure 13(b) is most easily understood by referencing it against Figure 1. The effects of dynamic normal grain growth are:

1. The $\gamma$-fiber is generally strengthened.

2. The $\{111\}\langle 110\rangle$ and $\{111\}\langle 112\rangle$ components of the $\gamma$ fiber, with respect to the specimen orientation, are particularly strengthened.

The calculated ODFs presented in Figure 13 demonstrate that the texture changes produced by crystal rotation during dislocation slip and the texture changes produced by dynamic normal grain growth in the IF steel are unique and can be separately identified.

Separating the effects of dynamic normal grain growth from crystal rotation allows testing of the "preferential dynamic grain growth mechanism" hypotheses developed by Fukutomi et al..$^{[12-15]}$ They hypothesized that dynamic grain growth prefers those grains oriented for (1) stability against deformation and (2) low Taylor factor. ${ }^{[15]}$ The first hypothesis that grains oriented for stability against deformation are preferred for dynamic grain growth is generally consistent with the experimental results. Figure 13(b) demonstrates strengthening of the $\{111\}\langle 110\rangle$ texture components, which are also strengthened by the crystal rotation shown in Figure 13(b) and are thus generally stable against deformation. It is noted that the (112)[11 0$]$ texture component strengthened by crystal rotation is not strengthened by dynamic normal grain growth, which may be marginally inconsistent with this hypothesis. The second hypothesis that grains oriented for low Taylor factors are preferred for dynamic growth is inconsistent with the experimental results. The texture components intensified by dynamic normal grain growth do not correlate with those having low Taylor factors.*

\footnotetext{
*Maps of Taylor factor can be readily generated using the MTEX software package for comparison against Figure 13.
}

Instead, Figure 13(b) indicates that the components of texture strengthened by dynamic normal grain growth have relatively high Taylor factors. The argument for the growth of grains with low Taylor factors by consuming grains with high Taylor factors is based upon dislocation density differences between these categories of grains. This argument is most persuasive when dislocation density is generally uniform within each grain. However, that is not the case for the IF steel deformed at $850^{\circ} \mathrm{C}$, as strong subgrain formation was observed in the specimens quenched after tensile deformation. The inhomogeneous distribution of dislocations between subgrain boundaries and subgrain interiors is one possible reason that the experimental data do not follow the hypothesized behavior. The experimental data suggest that further investigations are necessary to understand the mechanisms responsible for dynamic normal grain growth.

\section{CONCLUSIONS}

The following conclusions are drawn from the results of this experimental study.

1. The recrystallized microstructure of the IF steel contains equiaxed grains with an average lineal-intercept grain size of $13 \mu \mathrm{m}$, measured from BSE images, and a log-normal distribution of grain sizes. The recrystallization texture is dominated by a strong $\gamma$-fiber component.

2. For the range of deformation conditions examined at elevated temperatures from 840 to $890^{\circ} \mathrm{C}$, plastic flow is governed by the five-power creep mechanism, also know as dislocation climb controlled creep.

3. Plastic straining at $850^{\circ} \mathrm{C}$ produced dynamic grain growth in the IF steel that is significantly faster than static grain growth. No grain growth was observed after static annealing at $850^{\circ} \mathrm{C}$ for $100 \mathrm{~min}$. Plastic deformation at that temperature and a true-strain rate of $\dot{\epsilon}=10^{-4} \mathrm{~s}^{-1}$ to a tensile true strain of $\epsilon=0.2$ increased the grain size from 13 to $32 \mu \mathrm{m}$, by BSE measurements, within a total test time of $100 \mathrm{~min}$. This phenomenon is termed dynamic normal grain growth because it occurred during plastic straining, i.e., under dynamic conditions, and no abnormal grains were observed.

4. Dynamic normal grain growth increased grain size with increasing applied strain at $850^{\circ} \mathrm{C}$. The rate of grain growth with strain was measured using Eq. [3].

5. Dynamic normal grain growth created bimodal grain size distributions. These were interpreted as one log-normal distribution containing the grains increasing in size with strain and a second log-normal distribution of small grains that either did not grow or grew very little with strain.

6. The effects of crystal rotation and dynamic grain growth on texture evolution during tensile deformation were isolated using orientation distribution functions produced from experimental data.

7. Crystal rotation from plastic straining strengthened the $\alpha$-fiber component of texture relative to the specimen tensile axis, particularly those components of the $\alpha$-fiber that intersect the $\gamma$-fiber of the recrystallized condition, at the expense of other components within the $\gamma$-fiber.

8. Dynamic normal grain growth generally strengthened the $\gamma$-fiber and the $\{111\}\langle 110\rangle$ and $\{111\}\langle 112\rangle$ components in particular, relative to the specimen tensile axis.

9. Dynamic normal grain growth makes a unique contribution to crystallographic texture during plastic deformation at elevated temperature. 


\section{ACKNOWLEDGMENTS}

The authors gratefully acknowledge support from the National Science Foundation for this work under grant DMR-1507417 and for equipment acquired under DMR-9974476. The authors are grateful to Mr. Toshiyasu Ukena (Nippon Steel, retired) for his original research on this topic and for technical guidance very important in directing our studies. Mr. Thomas Cayia (Arcelor Mittal) is gratefully acknowledged for providing the interstitial-free steel material used in this study. The FEI XL30 ESEM and EBSD system used in this work is from the Department of Geological Sciences at the University of Texas at Austin. Sandia National Laboratories is a multimission laboratory managed and operated by National Technology \& Engineering Solutions of Sandia, LLC, a wholly owned subsidiary of Honeywell International, Inc., for the US DOE's National Nuclear Security Administration under contract DE-NA-0003525. The views expressed in the article do not necessarily represent the views of the US DOE or the United States Government.

\section{REFERENCES}

1. G. Krauss: Steels: ProcessingStructure, and Performance, ASM International, Materials Park, OH, 2005, vol. 21, pp. 226-30.

2. W.T. Lankford, S. C. Snyder, J. A. Bauscher, Trans. A.S.M., 1950, vol. 42, 1197-1232.

3. R.K. Ray, J.J. Jonas, and R.E. Hook: Int. Mater. Rev., 1994, vol. 93, pp. 129-72.

4. N. Yoshinaga, N. Sugiura, S.. Hiwatashi, K. Ushioda, and O. Kada: ISIJ Int., 2008, vol. 48, pp. 667-70

5. T. Ukena: CAMP-ISIJ, 1995, vol. 8, p. 1385 .

6. T. Ukena: $C A M P-I S I J, 1995$, vol. 8, p. 593

7. J.G. Byrne: Recovery, Recrystallization, and Grain Growth, The MacMillian Company, New York, 1965.

8. F.J. Humphreys and M. Hatherly: Recrystallization and Related Annealing Phenomena, Elsevier, New York, 2004.

9. D. Wilkinson and C. Caceres: Acta Metall., 1984, vol. 32, pp. $1335-45$.

10. P. Friedman and A. Ghosh: Metall. Mater. Trans. A, 1996 , vol. 27A, pp. 3827-39.

11. P. Bate, K. Hyde, S. Court, and F. Humphreys: Mater. Sci. Forum, 2004, vols. 447-448, pp. 61-66.

12. K. Okayasu and H. Fukutomi: J. Jpn. Inst. Met., 2006, vol. 70, pp. 562-67.

13. K. Okayasu, H. Takekoshi, and H. Fukutomi: Mater. Trans., 2007, vol. 48, pp. 2002-07.

14. K. Okayasu, S. Takahata, and H. Fukutomi: Mater. Sci. Forum, 2012, vols. 702-703, pp. 336-39.

15. Y. Onuki, R. Hongo, K. Okayasu, and H. Fukutomi: Acta Mater., 2013, vol. 61, pp. 1294-1302.

16. J.R. Ciulik and E.M. Taleff: Scripta Mater., 2009, vol. 61, pp. $895-98$.

17. N.A. Pedrazas, T.E. Buchheit, E.A. Holm, and E.M. Taleff: Mater. Sci. Eng. A, 2013, vol. 610, pp. 76-84.

18. D.L. Worthington, N.A. Pedrazas, and E.M. Taleff: Metall. Mater. Trans. A, 2013, vol. 44A, pp. 5025-38.

19. P.J. Noell, D.L. Worthington, and E.M. Taleff: Metall. Mater. Trans. A, 2015, vol. 46A, pp. 5709-18.

20. P.J. Noell and E.M. Taleff: Metall. Mater. Trans. A, 2016, vol. 47A, pp. 5023-36
21. P.J. Noell, D.L. Worthington, and E.M. Taleff: Mater. Sci. Eng. A, 2017, vol. 692, pp. 24-34.

22. P.J. Noell and E.M. Taleff: Metall. Mater. Trans. A, 2019, vol. $50 \mathrm{~A}$, pp. $4608-19$.

23. H.-J. Bunge, Texture Analysis in Materials Science: Mathematical Methods, digital edition, Butterworth \& Co., 1982.

24. U.F. Kocks, C.N. Tomé, and H.-R. Wenk: Texture and Anisotropy: Preferred Orientations in Polycrystals and their Effect on Materials Properties, Cambridge University Press, Cambridge, UK, 1998.

25. V. Randle: Microtexture Determination and Its Applications, The Institute of Materials, London, 1992.

26. ASTM International: Standard Designation E $18^{-17^{\epsilon 1}}$, ASTM International, West Conshohocken, PA, 2017.

27. R.E. Rupp, Dynamic Normal Grain Growth in BCC InterstitialFree Steel During Hot Deformation, Ph.D. Thesis, The University of Texas at Austin, August 2018.

28. ASTM International: Standard Designation E 112-13, ASTM International, West Conshohocken, PA, July 2013.

29. Wolfram Research, Inc.: Mathematica, Version 11.2, 2017.

30. N.A. Pedrazas, Dynamic Abnormal Grain Growth in Selected Refractory Metals, Ph.D. Thesis, The University of Texas at Austin, August 2013.

31. F. Bachmann, R. Hielscher, and H. Schaeben: Solid State Phenom., 2010, vol. 160, pp. 63-68.

32. MathWorks, Inc.: Matlab, Version R2014b, 2014.

33. ASTM International: Standard Designation E 2627-13, ASTM International, West Conshohocken, PA, 2013.

34. R.A. Lebensohn and C.N. Tome: Acta Metall. Mater., 1993, vol. 41, pp. 2611-24.

35. O.D. Sherby and P.M. Burke: Prog. Mater. Sci., 1968, vol. 13, pp. $325-90$.

36. J.E. Bird, A.K. Mukherjee, J.E. Dorn: in D.G. Brandon and A. Rosen, eds., Proceedings of the International Conference on Quantitative Relation Between Properties and Microstructure, Israel Universities Press, Haifa, Israel, 1969, pp. 255-342.

37. S. Karashima, T. Iikubo, and H. Oikawa: Trans. JIM, 1972, vol. 13, pp. 176-81.

38. R.G. Stang, W.D. Nix, and C.R. Barrett: Metall. Trans. A, 1975, vol. 6 A, pp. 2065-17.

39. C.R. Barrett, W.D. Nix, and O.D. Sherby: ASM Trans., 1966, vol. 59 , pp. 3-15.

40. O.D. Sherby, R.H. Klundt, and A.K. Miller: Metall. Trans. A, 1977, vol. 8A, pp. 843-50

41. T.R. McNelley, K. Oh-oishi, A.P. Zhilyaev, S. Swaminathan, P.E. Krajewski, and E.M. Taleff: Metall. Mater. Trans. A, 2008, vol. 39 A, pp. $50-64$.

42. S. Takaki, D. Akama, N. Nakada, and T. Tsuchiyama: Mater. Trans. (JIM), 2014, vol. 55, pp. 28-34.

43. M.E. Kassner: Fundamentals of Creep in Metals and Alloys, 3rd ed., Elsevier Science, Burlington, MA, 2015, pp. 7-102.

44. K. Werner: Z. Metallkd., 1948, vol. 39, pp. 1-9.

45. H. Oikawa: Technol. Rep. Tohoku Univ., 1982, vol. 47, pp. 67-77.

46. MTEX Documentation: https://mtex-toolbox.github.io/Documen tation.html, (2020).

47. T.G. Nieh, J. Wadsworth, and O.D. Sherby: Superplasticity in Metals and Ceramics, Cambridge University Press, New York, 1997.

48. O.D. Sherby and J. Wadsworth: Prog. Mater. Sci., 1989, vol. 33, pp. 169-221

49. T.E. Langdon: J. Mater. Sci., 2009, vol. 44, pp. 5998-6010.

50. C.S. Barrett and T.B. Massalski, Structure of Metals: Crystallographic Methods, Principles and Data, 3rd revised ed., Pergamon Press, Oxford, U.K., 1980.

Publisher's Note Springer Nature remains neutral with regard to jurisdictional claims in published maps and institutional affiliations. 